\title{
New Frontiers in Mechanosynthesis: Hydroxyapatite - and Fluorapatite - Based Nanocomposite Powders
}

\author{
Bahman Nasiri-Tabrizi, Abbas Fahami, \\ Reza Ebrahimi-Kahrizsangi and Farzad Ebrahimi \\ Additional information is available at the end of the chapter \\ http://dx.doi.org/10.5772/50160
}

\section{Introduction}

Mechanosynthesis process is a solid state method that takes advantage of the perturbation of surface-bonded species by pressure or mechanical forces to enhance the thermodynamic and kinetic reactions between solids. Pressure can be applied via conventional milling equipment, ranging from low-energy ball mills to high-energy stirred mills. In a mill, the reactants are crushed between the balls and wall (horizontal or planetary ball mill, attritor, vibratory ball mill), or between rings or ring and wall (multi-ring media mill) (Bose et al., 2009). These processes cause the creation of defects in solids; accelerate the migration of defects in the bulk, increase the number of contacts between particles, and renew the contacts. In these circumstances, chemical interaction occurs between solids (Avvakumov et al., 2002). This procedure is one of the most important fields of solid state chemistry, namely, the mechanochemistry of inorganic substances, which is intensively developed; so that, a large number of reviews and papers published on this subject in the last decades (Silva et al., 2003; Suryanarayana, 2001; De Castro \& Mitchell, 2002). The prominent features of this technique are that melting is not essential and that the products have nanostructural characteristics (Silva et al., 2003; Suryanarayana, 2001; De Castro \& Mitchell, 2002). In the field of bioceramics, high efficiency of the mechanochemical process opens a new way to produce commercial amount of nanocrystalline calcium phosphate-based materials. A review of scientific research shows that the mechanosynthesis process is a potential method to synthesis of nanostructured bioceramics (Rhee, 2002; Silva et al., 2004; Suchanek et al., 2004; Tian et al., 2008; Nasiri-Tabrizi et al., 2009; Gergely et al., 2010; Wu et al. 2011; Ramesh et al., 2012). 
On the other side, bioceramics play a vital role in several biomedical applications and have been expanding enormously the recent years (Adamopoulos \& Papadopoulos, 2007). Among different forms of bioceramics, particular attentions have been placed to calcium phosphates-based powders, granules, dense or porous bodies, and coatings for metallic or polymeric implants due to their excellent biocompatibility and osteointegration properties (Marchi et al., 2009). It is well known that hydroxyapatite $\left(\mathrm{HAp}: \mathrm{Ca}_{10}\left(\mathrm{PO}_{4}\right)_{6}(\mathrm{OH})_{2}\right)$ is a major mineral component of bones and teeth (Zhou \& Lee, 2011). Therefore, synthetic HAp has been extensively utilized as a bioceramic for maxillofacial applications owing to its excellent osteoconductive properties (Adamopoulos \& Papadopoulos, 2007). Besides this field, in a variety of other biomedical applications calcium phosphates have been used as matrices for controlled drug release, bone cements, tooth paste additive, and dental implants (Rameshbabu et al., 2006). Nevertheless, HAp intrinsic poor mechanical properties (strength, toughness and hardness), high dissolution rate in biological system, poor corrosion resistance in an acid environment and poor chemical stability at high temperatures have restricted wider applications in load-bearing implants (Fini et al., 2003; Chen et al., 2005).

According to the literature (Jallot et al., 2005), the biological and physicochemical properties of HAp can be improved by the substitution with ions usually present in natural apatites of bone. In fact, trace ions substituted in apatites can effect on the lattice parameters, the crystallinity, the dissolution kinetics and other physical properties (Mayer \& Featherstone, 2000). When $\mathrm{OH}^{-}$groups in HAp are partially substituted by $\mathrm{F}^{-}$, fluoride-substituted HAp (FHAp: $\left.\mathrm{Ca}_{10}\left(\mathrm{PO}_{4}\right)_{6}(\mathrm{OH})_{2-x} \mathrm{~F}_{\mathrm{x}}\right)$ is obtained. If the substitution is completed, fluorapatite (FAp: $\left.\mathrm{Ca}_{10}\left(\mathrm{PO}_{4}\right)_{6} \mathrm{~F}_{2}\right)$, is formed. When fluoride consumed in optimal amounts in water and food, used topically in toothpaste, and mouth rinses, it increases tooth mineralization and bone density, reduces the risk and prevalence of dental caries, and helps to promote enamel remineralization throughout life for individuals of all ages (Palmer \& Anderson, 2001). It is found that the incorporation of fluorine into HAp induced better biological response (Rameshbabu et al., 2006). On the other hand, the incorporation of bioinert ceramics and addition of appropriate amount of ductile metallic reinforcements into calcium phosphate-based materials has demonstrated significant improvement in structural features as well as mechanical properties. Therefore, improvements on structural, morphological, and mechanical properties of HAp ceramics have been tried by a number of researches (Cacciotti et al., 2009; Schneider et al., 2010; Farzadi et al., 2011; Pushpakanth et al., 2008; Rao \& Kannan, 2002; Viswanath \& Ravishankar, 2006; Gu et al., 2002; Ren et al., 2010). These studies have shown that such characteristics of HAp might be exceptionally strengthened by various methods such as making nanocomposites, use of different sintering techniques, and adding dopants. In the field of nanocomposites, an ideal reinforcing material for the HAp-based composites, which satisfies all of the requirements, has not yet been found. Thus, synthesis and characterization of novel nanostructured calcium phosphate-based ceramics provided the key target for current research. In most researches (Enayati-Jazi et al., 2012; Rajkumar et al., 2011; Choi et al., 2010), calcium phosphate-based nanocomposites were prepared using multiple wet techniques which ordinarily comprise of several step processes. Over the past decades, the mechanochemical synthesis has been extended for the production of a wide range of nanostructured materials (Suryanarayana, 2001), particularly for the synthesis of nanocrys- 
talline calcium phosphate-based ceramics (Rhee, 2002; Suchanek et al., 2004; Tian et al., 2008; Nasiri-Tabrizi et al., 2009; Gergely et al., 2010; Wu et al. 2011; Ramesh et al., 2012). The advantages of this procedure remains on the fact that melting is not necessary and the powders are nanocrystalline (Silva et al., 2007).

In this chapter, a new approach to synthesis of HAp- and FAp-based nanocomposites via mechanochemical process is reported. The effect of high-energy ball milling parameters and subsequent thermal treatment on the structural and morphological features of the nanocomposites were discussed in order to propose suitable conditions for the large scale synthesis of HAp- and FAp-based nanocomposites. Powder X-ray diffraction (XRD), Fourier transform infrared (FT-IR) spectroscopy, and energy dispersive X-ray spectroscopy (EDX) techniques are used to provide evidence for the identity of the samples. Transmission electron microscopy (TEM), Field-Emission Scanning Electron Microscope (FE-SEM), and scanning electron microscopy (SEM) are also utilized to study of the morphological features of the nanocomposites. Literature reported that the size and number of balls had no significant effect on the synthesizing time and grain size of FAp ceramics, while decreasing the rotation speed or ball to powder weight ratio increased synthesizing time and the grain size of FAp (Mohammadi Zahrani \& Fathi, 2009). On the other hand, our recent experimental results confirm that the chemical composition of initial materials and thermal annealing process are main parameters that affect the structural features (crystallinity degree, lattice strain, crystallite size) of the products via mechanochemical method (Nasiri-Tabrizi et al., 2009; Honarmandi et al., 2010; Ebrahimi-Kahrizsangi et al., 2010; Fahami et al., 2011; EbrahimiKahrizsangi et al., 2011; Fahami et al., 2012). Consequently, the present chapter is focused on the mechanochemical synthesize of HAp- and FAp-based nanocomposites. In the first part of this chapter, an overview of recent development of ceramic-based nanocomposites in biomedical applications and mechanochemical process are provided. The other sections describe the application of these procedures in the current study. The effects of milling media and atmosphere to prepare novel nanostructured HAp-based ceramics are studied. Moreover, mechanochemical synthesis and characterization of nanostructured FAp-based bioceramics are investigated.

\section{Recent developments of ceramic-based nanocomposites for biomedical applications}

Over the past decades, innovations in the field of bioceramics such as alumina, zirconia, hydroxyapatite, fluorapatite, tricalcium phosphates and bioactive glasses have made significant contribution to the promotion of modern health care industry and have improved the quality of human life. Bioceramics are mainly applied as bone substitutes in biomedical applications owing to their biocompatibility, chemical stability, and high wear resistance. However, the potential of bioceramics in medical applications depends on its structural, morphological, mechanical, and biological properties in the biological environment. The first successful medical application of calcium phosphate bioceramics in humans is reported in 1920 (Kalita et al., 2007). After that the first dental application of these ceramics in animals 
was described in 1975 (Kalita et al., 2007). In a very short period of time, bioceramics have found various applications in replacements of hips, knees, teeth, tendons and ligaments and repair for periodontal disease, maxillofacial reconstruction, augmentation and stabilization of the jawbone and in spinal fusion (Kalita et al., 2007).

Today, many specialty ceramics and glasses have been developed for use in dentistry and medicine, e.g., dentures, glass-filled ionomer cements, eyeglasses, diagnostic instruments, chemical ware, thermometers, tissue culture flasks, fiber optics for endoscopy, and carriers for enzymes and antibodies (Hench, 1998). Among them, calcium phosphate-based bioceramics have been utilized in the field of biomedical engineering due to the range of properties that they offer, from tricalcium phosphates $(\alpha / \beta$-TCP) being resorbable to HAp being bioactive (Ducheyne \& Qiu, 1999). Hence, different phases of calcium phosphate-based bioceramics are used depending upon whether a resorbable or bioactive material is desired. The phase stability of calcium phosphate-based bioceramics depends significantly upon temperature and the presence of water, either during processing or in the use environment. It is found that at body temperature; only two calcium phosphates are stable in contact with aqueous media, such as body fluids. These stable phases are $\mathrm{CaHPO}_{4} \cdot 2 \mathrm{H}_{2} \mathrm{O}$ (dicalcium phosphate, brushite) and HAp at $\mathrm{pH}<4.2$ and $\mathrm{pH}>4.2$, respectively (Hench, 1998). At higher temperatures, other phases, such as $\alpha / \beta$-TCP and tetracalcium phosphate $\left(\mathrm{Ca}_{4} \mathrm{P}_{2} \mathrm{O}_{9}\right)$ are present. The final microstructure of TCP will contain $\beta$ or $\alpha$-TCP depending on their cooling rate. Rapid cooling from sintering temperature gives rise to $\alpha$-TCP phase only, whereas slow furnace cooling leads to $\beta$-TCP phase only. Any moderate cooling rate, in between these two results mixed phase of both $\beta$ and $\alpha$-TCP (Nath et al., 2009).

One of the primary restrictions on clinical use of bioceramics is the uncertain lifetime under the complex stress states, slow crack growth, and cyclic fatigue that result in many clinical applications. Two creative approaches to these mechanical limitations are use of bioactive ceramics as coatings, and the biologically active phase in composites. Because of the anisotropic deformation and fracture characteristics of cortical bone, which is itself a composite of compliant collagen fibrils and brittle HAp crystals, the Young's modulus varies 7-25 GPa, the critical stress intensity ranges $\sim 2-12 \mathrm{MPa} . \mathrm{m}^{1 / 2}$, and the critical strain intensity increases from as low as $\sim 600$ $\mathrm{J} . \mathrm{m}^{-2}$ to as much as $5000 \mathrm{~J} . \mathrm{m}^{-2}$, depending on orientation, age, and test condition. On the contrary, most bioceramics are much stiffer than bone and many exhibit poor fracture toughness (Hench, 1998). Therefore, the only materials that exhibit a range of properties equivalent to bone are composites. For this reason, many attempts have been made to improve the mechanical properties as well as structural features through the incorporation of ceramic second phases (Viswanath \& Ravishankar, 2006; Evis, 2007; Nath et al., 2009; Ben Ayed \& Bouaziz, 2008). These studies have shown that the mechanical properties of HAp and fluoridated HAp might be exceptionally strengthened by composite making technique.

It is found that (Kong et al., 1999) the following conditions should be satisfied to be effective as a reinforcing agent for a ceramic matrix composite material. First, the strength and the elastic modulus of the second phase must be higher than those of the matrix. Second, the interfacial strength between the matrix and the second phase should be neither too weak nor too strong. Indeed, for an appropriate interfacial strength, no excessive reaction should oc- 
cur between the matrix and the second phase. Third, the coefficient of thermal expansion (CTE) of the second phase should not differ too much from that of the matrix in order to prevent micro-cracks formation in densification process. Fourth, in the case of biomaterials, the biocompatibility of the reinforcing agent is another crucial factor that should be considered. Nevertheless, an ideal reinforcing material for the calcium phosphate-based composites, which satisfies all of requirements, has not yet been found. So, some attempts have been made to develop HAp- and fluorhydroxyapatite-based composites such as $\mathrm{HAp}-\mathrm{Al}_{2} \mathrm{O}_{3}$ (Viswanath \& Ravishankar, 2006), $\mathrm{HAp}-\mathrm{ZrO}_{2}$ (Evis, 2007), $\mathrm{HAp}-\mathrm{TiO}_{2}$ (Nath et al., 2009), FHAp- $\mathrm{Al}_{2} \mathrm{O}_{3}$ (Adolfsson et al., 1999), $\mathrm{FHAp}-\mathrm{ZrO}_{2}$ (Ben Ayed \& Bouaziz, 2008), poly(lactideco-glycolide)/ $\beta$-TCP (Jin. et al., 2010), polyglycolic acid (PGA) $/ \beta-$ TCP (Cao \& Kuboyama, 2010), and HAp-CNT (Lee et al., 2011) composites. These experimental studies exhibited that interfacial reactions occurred during the high temperature processing of composites due to the large interfacial area available for the reactions. Interfacial reactions result in the formation of new phases, influence densification, mechanical properties and even degrade the biological properties of the composite in some cases which often limit their performance (Viswanath \& Ravishankar, 2006). Hence, control over nanocomposite characteristics is a challenging task.

\section{Mechanosynthesis of ceramic-based nanocomposites}

To date, several approaches, including wet chemical methods (Mobasherpour et al., 2007; Kivrak \& Tas, 1998), hydrothermal processes (Liu et al., 2006), solid-state reaction (Silva et al., 2003), and sol-gel method (Balamurugan et al., 2002), have been developed for synthesis of nanobioceramics. Among them, mechanochemical process has been extended for the production of a wide range of nanostructured materials (Suryanarayana, 2001; De Castro \& Mitchell, 2002). According to literature (Bose et al., 2009), mechanochemical synthesis was originally designed for the production of oxide dispersion-strengthened (ODS) alloys. Over the past 20 years, however, the number of available mechanochemical synthesis has grown, such that Nowadays it is used for the fabrication of a wide range of advanced materials, both metallic and nonmetallic in composition. In mechanosynthesis, the chemical precursors typically consist of mixtures of oxides, chlorides and/or metals that react either during milling or during subsequent thermal treatment to form a composite powder consisting of the dispersion of ultrafine particles within a soluble salt matrix. The ultrafine particle is then recovered by selective removal of the matrix phase through washing with an appropriate solvent.

Mechanochemical approach is a very effective process for synthesizing nanocomposites with various classes of compounds: metals, oxides, salts, organic compounds in various combinations. For example, Khaghani-Dehaghani et al. (Khaghani-Dehaghani et al., 2011) synthesized $\mathrm{Al}_{2} \mathrm{O}_{3}-\mathrm{TiB}_{2}$ nanocomposite by mechanochemical reaction between titanium dioxide, acid boric and pure aluminum according to the following reactions: 


$$
\begin{gathered}
2 \mathrm{H}_{3} \mathrm{BO}_{3} \rightarrow \mathrm{B}_{2} \mathrm{O}_{3}+3 \mathrm{H}_{2} \mathrm{O} \\
3 \mathrm{TiO}_{2}+3 \mathrm{~B}_{2} \mathrm{O}_{3}+10 \mathrm{Al} \rightarrow 3 \mathrm{TiB}_{2}+5 \mathrm{Al}_{2} \mathrm{O}_{3}
\end{gathered}
$$

Titanium diboride has an attractive combination of high Vickers hardness, electrical conductivity, excellent chemical resistance to molten nonferrous metals and relatively low specific gravity ( $\mathrm{Gu}$ et al., 2008). However, titanium diboride has poor fracture toughness and impact strength. Thus, the composites of $\mathrm{TiB}_{2}$ such as $\mathrm{Al}_{2} \mathrm{O}_{3}-\mathrm{TiB}_{2}$ improve those mechanical properties. These nanocomposites are useful in variety of applications such as cutting tools, wear-resistant substrates, and lightweight armor (Mishra et al., 2006). Results reveal that the $\mathrm{Al}_{2} \mathrm{O}_{3}-\mathrm{TiB}_{2}$ nanocomposite was successfully synthesized after $1.5 \mathrm{~h}$ of milling. Also, the determined amounts of structural features demonstrate that after $20 \mathrm{~h}$ of milling the steady state was obtained. Increasing milling time up to $40 \mathrm{~h}$ had no significant effect other than refining the crystallite size. The SEM and TEM observations show that increase of milling time was associated with decrease of powder particles, so that a fine structure was produced after $40 \mathrm{~h}$ of milling. Figure 1 shows the morphological features of the $\mathrm{Al}_{2} \mathrm{O}_{3}-\mathrm{TiB}_{2}$ nanocomposite powders after $40 \mathrm{~h}$ of milling by SEM and TEM. It is clear that the particles exhibited high affinity to agglomerate. The agglomerates include fine particles of $\mathrm{TiB}_{2}$ and $\mathrm{Al}_{2} \mathrm{O}_{3}$.

Thermodynamic studies, based on thermodynamic databases, show that the change in Gibbs free energy of the reduction of boron oxide and titanium oxide with aluminum (Eqs. (3) and (4)) is favorable at room temperature.

$$
\begin{aligned}
& 4 \mathrm{Al}+3 \mathrm{TiO}_{2} \rightarrow 2 \mathrm{Al}_{2} \mathrm{O}_{3}+3 \mathrm{Ti} \\
& \Delta \mathrm{G}_{298 \mathrm{~K}}^{\circ}=-495.488 \mathrm{~kJ}, \Delta \mathrm{H}_{298 \mathrm{~K}}^{\circ}=-516.306 \mathrm{~kJ} \\
& 2 \mathrm{Al}+\mathrm{B}_{2} \mathrm{O}_{3} \rightarrow \mathrm{Al}_{2} \mathrm{O}_{3}+2 \mathrm{~B} \\
& \Delta \mathrm{G}_{298 \mathrm{~K}}^{\circ}=-389.053 \mathrm{~kJ}, \Delta \mathrm{H}_{298 \mathrm{~K}}^{\circ}=-403.338 \mathrm{~kJ}
\end{aligned}
$$

It is well known if a reaction is highly exothermic, the impact of the milling balls can initiate a mechanically induced self-sustaining reaction (MSR) (Xia et al., 2008). MSR was usually observed in highly exothermic reactions. The ignition of MSR takes place after a certain activation time, during which the powder mixtures reach a critical state due to the physical and chemical changes caused by ball milling (Takacs, 2002; Takacs et al., 2006). That certain activation time depends mainly on the exothermicity of the process, the milling conditions and the mechanical properties of the raw materials. Takacs (Takacs, 2002) showed that a reaction can propagate in the form of a self sustaining process, if $\Delta \mathrm{H} / \mathrm{C}$, the magnitude of the heat of reaction divided by the room temperature heat capacity of the products, is higher than about 2000 $\mathrm{K}$. The calculations on the system $\mathrm{Al}-\mathrm{B}_{2} \mathrm{O}_{3}-\mathrm{TiO}_{2}$ show that the value of $\Delta \mathrm{H} / \mathrm{C}$ is about $5110 \mathrm{~K}$. Therefore, the proposed reactions occurred through an expanded MSR reaction in milled samples which led to the formation of $\mathrm{Al}_{2} \mathrm{O}_{3}-\mathrm{TiB}_{2}$ nanocomposite after short milling times. 


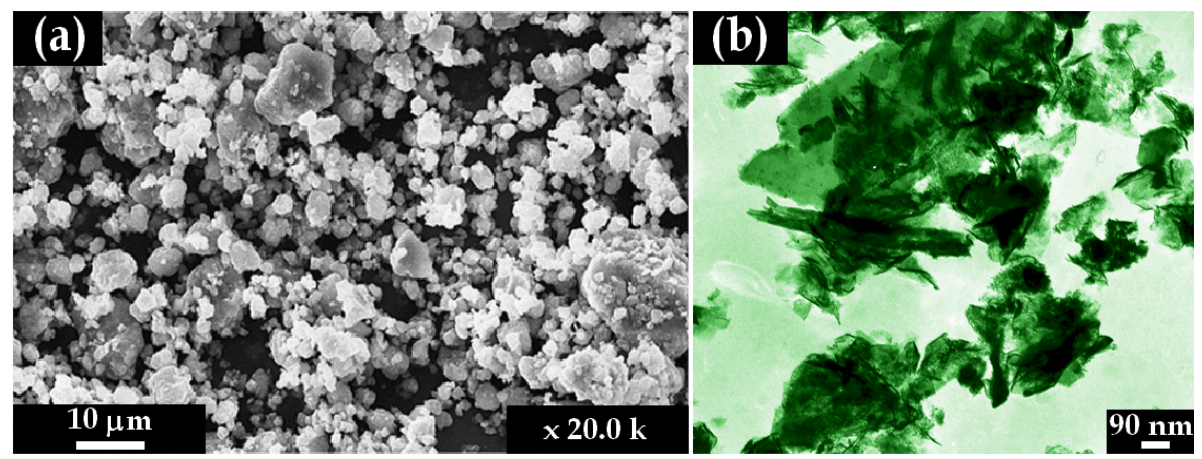

Figure 1. a) SEM micrograph and (b) TEM image of $\mathrm{Al}_{2} \mathrm{O}_{3}-\mathrm{TiB}_{2}$ nanocomposite after $40 \mathrm{~h}$ of milling (Khaghani-Dehaghani et al., 2011).

\subsection{Mechanochemical synthesize of hydroxyapatite nanostructures}

HAp and its isomorphous modifications are valuable and prospective materials in biomedical applications. Therefore, a large number of studies was performed on this subject in the last decade (Rhee, 2002; Silva et al., 2004; Suchanek et al., 2004; Tian et al., 2008; Nasiri-Tabrizi et al., 2009; Gergely et al., 2010; Wu et al. 2011; Ramesh et al., 2012). Generally, the fabrication methods of HAp nanostructures can be classified into two groups: wet and dry (Rhee, 2002). The advantage of the wet process is that the by-product is almost water and as a result the probability of contamination during the process is very low. On the other hand, the dry process has benefit of high reproducibility and low processing cost in spite of the risk of contamination during milling. Furthermore, the dry mechanochemical synthesis of HAp presents the advantage that melting is not necessary and the powder obtained is nanocrystalline. The calcium and phosphorous compounds used as the starting materials in the dry process are dicalcium phosphate anhydrous $\left(\mathrm{CaHPO}_{4}\right)$, dicalcium phosphate dihydrate $\left(\mathrm{CaHPO}_{4} \cdot 2 \mathrm{H}_{2} \mathrm{O}\right)$, monocalcium phosphate monohydrate $\left(\mathrm{Ca}\left(\mathrm{H}_{2} \mathrm{PO}_{4}\right)_{2} \cdot \mathrm{H}_{2} \mathrm{O}\right)$, calcium pyrophosphate $\left(\mathrm{Ca}_{2} \mathrm{P}_{2} \mathrm{O}_{7}\right)$, calcium carbonate $\left(\mathrm{CaCO}_{3}\right)$, calcium oxide $(\mathrm{CaO})$, and calcium hydroxide $\left(\mathrm{Ca}(\mathrm{OH})_{2}\right)$, etc.

Otsuka et al. (Otsuka et al., 1994) investigated the effect of environmental conditions on the crystalline transformation of metastable calcium phosphates during grinding. Based on the results, the mixture of $\mathrm{CaHPO}_{4}$ and $\mathrm{Ca}(\mathrm{OH})_{2}$ transformed into low-crystallinity HAp after grinding in air. Nevertheless, under $\mathrm{N}_{2}$ atmosphere, a mixture of initial materials did not transform into HAp. After that, Toriyama et al. (Toriyama et al., 1996) proposed a method to prepare powders and composite ceramic bodies with a matrix comprising HAp. The powders Was produced by the utilization of a simple and economic mechanochemical method. The composite ceramic bodies were easily obtained by simple firing of the powders at a suitable temperature $(1250 \mathrm{C})$. After sintering, the obtained products exhibited a flexural strength of more than $100 \mathrm{MPa}$ in standard samples. This value is significantly higher than that usually attainable with commercially available powders $(60 \mathrm{MPa})$. In another research 
(Yeong et al., 2001), nanocrystalline HAp phase has been produced by high-energy mechanical activation in a dry powder mixture of $\mathrm{CaO}$ and $\mathrm{CaHPO}_{4}$. The initial stage of mechanical activation resulted in a significant refinement in crystallite and particle sizes, together with a degree of amorphization in the starting powder mixture. A single-phase HAp of high crystallinity was attained by $>20 \mathrm{~h}$ of mechanical activation. The resulting HAp powder exhibits an average particle size of $\sim 25 \mathrm{~nm}$. It was sintered to a density of $98.20 \%$ theoretical density at $1200 \mathrm{C}$ for $2 \mathrm{~h}$. The hardness increases almost linearly with rising sintering temperature from 900 to $1200 \mathrm{C}$, where it reaches a maximum of $5.12 \mathrm{GPa}$. This is followed by a slight decrease, to $4.92 \mathrm{GPa}$, when the sintering temperature is raised to $1300 \mathrm{C}$. Afterward, Rhee (Rhee, 2002) synthesized HAp powder by mechanochemical reaction between $\mathrm{Ca}_{2} \mathrm{P}_{2} \mathrm{O}_{7}$ and $\mathrm{CaCO}_{3}$. The two powders were mixed in acetone and water, respectively, and the single phase of HAp was observed to occur only in the powder milled in water, without the additional supply of water vapor during heat-treatment at $1100 \mathrm{C}$ for $1 \mathrm{~h}$. The results indicated that the mechanochemical reaction could supply enough amount of hydroxyl group to the starting powders to form a single phase of HAp. Therefore, the powder of high crystalline HAp can be obtained by the simple milling in water and subsequent heat-treatment. With the development of nanostructured materials using mechanochemical processes, nanocrystalline powders of HAp was produced in 2003 by Silva et al. (Silva et al., 2003). To produce nanocrystalline powders of HAp, five different experimental procedures in a pure dry process were utilized. For four different procedures, HAp was obtained after a couple of hours of milling (in average $60 \mathrm{~h}$ of milling, depending in the reaction procedure). In the preparation of nanocrystalline HAp, commercial oxides $\mathrm{Ca}_{3}\left(\mathrm{PO}_{4}\right)_{2} \cdot \mathrm{xH}_{2} \mathrm{O}, \mathrm{Ca}(\mathrm{OH})_{2}, \mathrm{CaHPO}_{4}, \mathrm{P}_{2} \mathrm{O}_{5}$, $\mathrm{CaCO}_{3}$ and $\left(\mathrm{NH}_{4}\right) \mathrm{H}_{2} \mathrm{PO}_{4}$ were used in the HAp preparation. This milling process, presents the advantage that melting is not necessary and the powder obtained is nanocrystalline with crystallite size in the range of $22 \mathrm{~nm}$ to $39 \mathrm{~nm}$. Subsequently, Silva et al. (Silva et al., 2004) synthesized nanocrystalline powders of HAp using three different experimental procedures (HAPA: $\mathrm{Ca}\left(\mathrm{H}_{2} \mathrm{PO}_{4}\right)_{2}+\mathrm{Ca}(\mathrm{OH})_{2} ; \mathrm{HAPB}: \mathrm{Ca}\left(\mathrm{H}_{2} \mathrm{PO}_{4}\right)_{2}+\mathrm{CaCO}_{3}$; and $\mathrm{HAPC}: \mathrm{CaHPO}_{4}+\mathrm{CaCO}_{3}$ ). Nanocrystalline HAp was obtained after 5, 10 and $15 \mathrm{~h}$ of milling in the reactions HAPA and HAPB, but it is necessary $15 \mathrm{~h}$ of milling in the reaction HAPC to obtain HAP. Moreover, in order to improve the mechanical properties of HAp calcium phosphate ceramics, with titanium $(\mathrm{CaP}-\mathrm{Ti})$ and zirconium $(\mathrm{CaP}-\mathrm{Zr})$, were prepared by dry ball milling using two different experimental procedures: CaP-Ti1: $\mathrm{Ca}\left(\mathrm{H}_{2} \mathrm{PO}_{4}\right)_{2}+\mathrm{TiO}_{2} ; \mathrm{CaP}-\mathrm{Ti2}: \mathrm{CaHPO}_{4}+$ $\mathrm{TiO}_{2}$; and CaP-Zr1: $\mathrm{Ca}\left(\mathrm{H}_{2} \mathrm{PO}_{4}\right)_{2}+\mathrm{ZrO}_{2}, \mathrm{CaP}-\mathrm{Zr} 2: \mathrm{CaHPO}_{4}+\mathrm{ZrO}_{2}$. The calcium titanium phosphate phase, $\mathrm{CaTi}_{4} \mathrm{P}_{6} \mathrm{O}_{24}$, was produced in the reaction $\mathrm{CaP}-\mathrm{Ti1}$. In the reactions CaP$\mathrm{Ti} 2, \mathrm{CaP}-\mathrm{Zr} 1$ and $\mathrm{CaP}-\mathrm{Zr} 2$, it was not observed the formation of any calcium phosphate phase even after $15 \mathrm{~h}$ of dry mechanical alloying.

Nanocrystalline HAp powders were synthesized by the mechanochemical-hydrothermal method using emulsion systems consisting of aqueous phase, petroleum ether (PE) as the oil phase and biodegradable Tomadol 23-6.5 as the nonionic surfactant (Chen et al., 2004). $\left(\mathrm{NH}_{4}\right)_{2} \mathrm{HPO}_{4}$ and $\mathrm{Ca}\left(\mathrm{NO}_{3}\right)_{2}$ or $\mathrm{Ca}(\mathrm{OH})_{2}$ were used as the phosphorus and calcium sources, respectively. The calcium source and emulsion composition had significant effects on the stoichiometry, crystallinity, thermal stability, particle size, and morphology of final products. 
Disperse HAp crystals with a $160 \mathrm{~nm}$ length were formed in an emulsion system containing 10 $w \mathrm{t} \% \mathrm{PE}, 60 \mathrm{wt} \%$ water, and $30 \mathrm{wt} \%$ surfactant. The HAp particles had needle morphology with a specific surface area of $190 \mathrm{~m}^{2} / \mathrm{g}$. According to obtained results, HAp nanopowders with specific surface areas in the range of $72-231 \mathrm{~m}^{2} / \mathrm{g}$ were produced. In the same year, Mochales et al. (Mochales et al., 2004) investigated the possibility of mechanochemistry to synthesize calcium deficient HAp (CDHA) with an expected molar calcium to phosphate $(\mathrm{Ca} / \mathrm{P})$ ratio \pm 0.01 . To optimize the experimental conditions of CDHA preparation from dicalcium phosphate dihydrate (DCPD) and calcium oxide by dry mechanosynthesis reaction, the kinetic study was carried out with two different planetary ball mills (Retsch or Fritsch Instuments). Results obtained with the two mills led to the same conclusions although the values of the rate constants of DCPD disappearance and times for complete reaction were very different. Certainly, the origin of these differences was from the mills used, thus the influence of instrumental parameters such as the mass and the surface area of the balls or the rotation velocity were examined on the mechanochemical reaction kinetics of DCPD with $\mathrm{CaO}$. Results exhibited that the DCPD reaction rate constant and the inverse of the time for complete disappearance of $\mathrm{CaO}$ both vary linearly with (i) the square of the rotation velocity, (ii) the square of eccentricity of the vial on the rotating disc and (iii) the product of the mass by the surface area of the balls. The consideration of these four parameters allows the transposition of experimental conditions from one mill to another or the comparison between results obtained with different planetary ball mills. Gonzalez et al. (Gonzalez et al., 2006) studied the mechanochemical transformation of two mixtures: $\mathrm{Ca}(\mathrm{OH})_{2}-\left(\mathrm{NH}_{4}\right)_{2} \mathrm{HPO}_{4}$ and $\mathrm{Ca}(\mathrm{OH})_{2}-\mathrm{P}_{2} \mathrm{O}_{5}$, milled in a mortar dry grinder for different periods of time. Mechanical grinding and thermal treatment was a successful method to obtained biphasic mixtures of HAp/ $\beta$-TCP. Amorphization, for both reactant mixtures, was observed after prolonged milling, $17.5 \mathrm{~h}$ for $\mathrm{Ca}(\mathrm{OH})_{2}-\left(\mathrm{NH}_{4}\right)_{2} \mathrm{HPO}_{4}$ mixture and $5 \mathrm{~h}$ for the $\mathrm{Ca}(\mathrm{OH})_{2}-\mathrm{P}_{2} \mathrm{O}_{5}$ mixture. The composition of the milled powders varied in the range of $1.50<\mathrm{Ca} / \mathrm{P}<1.67$ for different milling periods. Calcination of milled powders of both mixtures at $800 \mathrm{C}$ led to the formation of HAp and $\beta$-TCP, with an average particle size of $200 \mathrm{~nm}$. Further, the $\mathrm{Ca} / \mathrm{P}$ ratio affects the proportion of HAp and $\beta$-TCP phases obtained after thermal treatment. Also, Kano et al. (Kano et al., 2006) developed a novel mechanochemical process to prepare HAp fine particles. For this aim, a non-thermal process for dechlorinating of Polyvinyl chloride (PVC) was utilized. This process was composed of two steps: The first step was to grind the PVC waste with an active grinding additive such as $\mathrm{CaO}$, leading to transformation of organic chlorine into water soluble chloride mechanochemically. The second step is to remove the formed chloride from the milled product by washing with water. When the filtrate was mixed with solution which contains phosphate ion $\mathrm{PO}_{4}{ }^{2-}, \mathrm{HAp}$ fine particles formed which has sorption ability for heavy metals such as $\mathrm{Pb}^{2+}$. El Briak-BenAbdeslam et al. (El Briak-BenAbdeslam et al., 2008) investigated the influence of water addition on the kinetics of the mechanochemical reaction of dicalcium phosphate dihydrate with calcium oxide. The DCPD disappearance rate constant $\mathrm{k}$ 
and the final reaction time $t_{\mathrm{f}}$ were determined in each case and correlated with the water content present in the slurry. Results showed that the addition water (i) slowed down the reaction rate and (ii) increased the powder contamination by mill material (hard porcelain) due to ball and vial erosion; and that (iii) wet milling did not generate the expected products, in contrast to dry grinding, because porcelain induced HAp decomposition with the formation of $\beta$-TCP and silicon-stabilized tricalcium phosphate. Consequently, dry mechanosynthesis appears preferable to wet milling in the preparation of calcium phosphates of biological interest.

\subsubsection{Single-crystal hydroxyapatite nanoparticles}

A new approach to mechanochemical synthesis of HAp nanostructures was developed in 2009 by Nasiri-Tabrizi et al. (Nasiri-Tabrizi et al., 2009). Single-crystal HAp nanorods and nanogranules synthesized successfully by a mechanochemical process using two distinct experimental procedures.

$$
\begin{gathered}
6 \mathrm{CaHPO}_{4}+4 \mathrm{Ca}(\mathrm{OH})_{2} \rightarrow \mathrm{Ca}_{10}\left(\mathrm{PO}_{4}\right)_{6}(\mathrm{OH})_{2}+6 \mathrm{H}_{2} \mathrm{O} \\
4 \mathrm{CaCO}_{3}+6 \mathrm{CaHPO}_{4} \rightarrow \mathrm{Ca}_{10}\left(\mathrm{PO}_{4}\right)_{6}(\mathrm{OH})_{2}+4 \mathrm{CO}_{2}+2 \mathrm{H}_{2} \mathrm{O}
\end{gathered}
$$

The feasibility of using polymeric milling media to prepare HAp nanoparticles is described. By controlling the temperature and milling time during mechanical activation (45-min milling steps with 15-min pauses), powders with three different crystallite size, lattice strain and crystallinity degrees are produced. Figure 2 presents the XRD patterns of reactions 5 and 6 , respectively. The XRD patterns show that the product of reaction 5 is HAp. The extra peaks $\left(\mathrm{CaHPO}_{4}\right.$ च) occurred in $2 \theta=26.59$ and 30.19 , consecutively. In reaction 6 , the extra peaks are not observed after 40, 60 and $80 \mathrm{~h}$ of milling and the only detected phase is HAp, as shown in Figure 2(b). Therefore, during milling process, $\mathrm{CaHPO}_{4}$ is a compound that should be avoided if the purpose is to achieve pure HAp without any extra phase presentation. In order to determine crystallite size and lattice strain in activated samples, the full width at half maximum (FWHM) of each peak is usually considered. Furthermore, the fraction of crystalline phase $\left(X_{c}\right)$ in the HAp powders is evaluated by Landi equation (Landi et al., 2000).

According to obtained data, the crystallite size decreases and the lattice strain increases with increase of milling time. However, the rate of both variations, i.e. increasing lattice strain and decreasing crystallite size, decreases by increasing the milling time. Furthermore, the obtained data show that by choosing the total milling time to $80 \mathrm{~h}$ for reaction 5 , the crystallinity degree increases first and reaches to a maximum at $60 \mathrm{~h}$ of milling, and then by further increasing the milling time to $80 \mathrm{~h}$, the crystallinity degree decreases. Moreover, the increase of HAp crystallinity compared to the increase of milling time was not linear. The fraction of crystalline phase in the HAp powders from reaction 6 indicates that by increasing the milling time from 40 to 80 $\mathrm{h}$, the crystallinity degree decreases mostly after $60 \mathrm{~h}$ and reaches to a minimum at $80 \mathrm{~h}$ of mill- 
ing time. Based on these results, we conclude that the chemical composition of initial materials and the milling time are important parameters that affect the structural properties of product via mechanochemical process.

The morphological features of the synthesized HAp products were further examined by TEM technique. Figures 3 and 4 show the TEM micrographs of nanorods and nanogranules, respectively. Figure 3a shows that the sample possesses a mostly rod-like structure after $60 \mathrm{~h}$ milling time in polymeric milling vial for reaction 5 . In Figure $3 b$, it can be seen that the morphology of nanocrystalline HAp after $80 \mathrm{~h}$ milling time, similar to $60 \mathrm{~h}$, is also the rod shape; although, few particles appear to be close to a spherical shape. Using HAp nanorods as raw materials is an effective way to obtain dense bioceramics with high mechanical properties. Hence, this product may be used as strength enhancing additives for the preparation of the HAp ceramics or biocompatible nanocomposites.
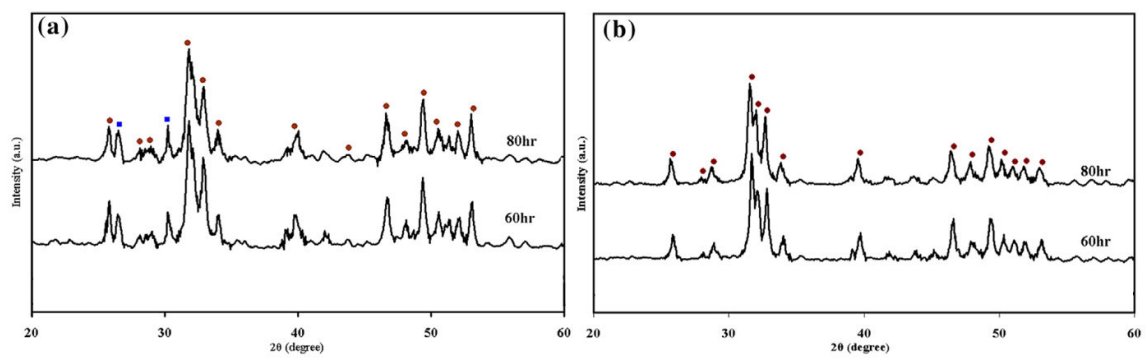

Figure 2. XRD patterns of samples milled for 60 and 80 h, (a) reaction 5 and (b) reaction 6. (Nasiri-Tabrizi et al., 2009).
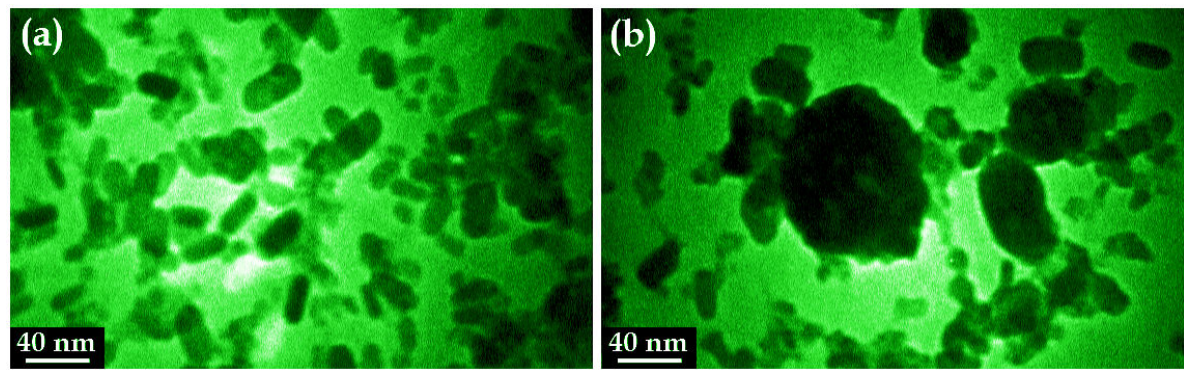

Figure 3. Typical TEM micrograph of nanorods HAp after $60 \mathrm{~h} \mathrm{(a)} \mathrm{and} 80 \mathrm{~h}$ (b) milling time for reaction 5 (Nasiri-Tabrizi et al., 2009).

In reaction 5, more agglomeration also occurs by increasing milling time from $60 \mathrm{~h}$ to $80 \mathrm{~h}$. In fact, the obtained product nearly had a uniform geometry distribution just after $60 \mathrm{~h}$ milling time. Although, it may appear some ellipse or round like shapes from this image, it is due to the axis orientation of nanorods with respect to the image plane. In other words, if 
the rod axis is perpendicular or oblique on the image plane, the rod may be seen as a full circle or ellipse, respectively. Despite of previous research that a perfect spherical shape rarely observed in the mechanically alloyed powders, nanosphere particles were successfully obtained. In Figure 4, it can be seen that the morphology of nanocrystalline HAp for reaction 6, either after 60 or $80 \mathrm{~h}$ milling time, is absolutely spherical granules with a reasonable smooth geometry.

Therefore, we reach to an important conclusion that using polyamide- 6 milling vial leads to the spherical granules HAp. Since spherical geometry compared to irregular shape is important for achieving osseointegration (Komlev et al., 2001; Nayar et al., 2006; Hsu et al., 2007), the latest product is well preferred for medical applications. Similar to previous reaction, the obtained product after $60 \mathrm{~h}$ has a better uniform geometry distribution than one after $80 \mathrm{~h}$ milling time. It should be noted that the HAp particles out of reaction 5 are in average length of $17 \pm 8$ $\mathrm{nm}$ and $13 \pm 7 \mathrm{~nm}$ after 60 and $80 \mathrm{~h}$ milling time, respectively. Similarly, the HAp particles out of reaction 6 are in average diameter of $16 \pm 9 \mathrm{~nm}$ and $15 \pm 8 \mathrm{~nm}$ after 60 and $80 \mathrm{~h}$ milling time. Based on obtained data, the maximum particle distribution is below the crystallite size which is estimated from the line broadening of the given X-ray diffraction peak.
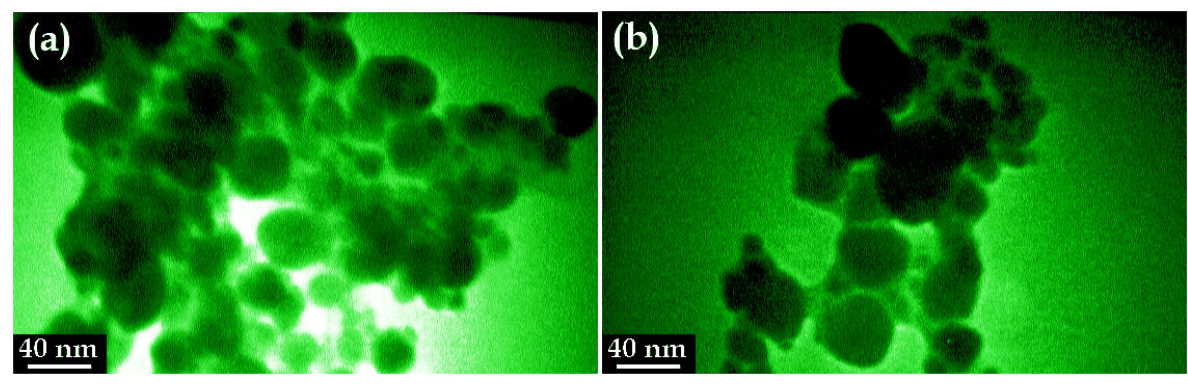

Figure 4. Typical TEM micrograph of nanospheres HAp after $60 \mathrm{~h}$ (a) and $80 \mathrm{~h}$ (b) milling time for reaction 6 (NasiriTabrizi et al., 2009).

Thus, after $80 \mathrm{~h}$ milling time, we ascertain that this method gives rise to the single-crystal HAp with their average size below $20 \mathrm{~nm}$ and $23 \mathrm{~nm}$ for reactions 6 and 7, respectively. In fact, a novel method for the synthesis of nanosize single-crystal HAp is developed in both spherical and rod-like particles.

\subsubsection{Milling media effects on structural features of hydroxyapatite}

Honarmandi et al. (Honarmandi et al., 2010) investigated the effects of milling media on synthesis, morphology and structural characteristics of single-crystal HAp nanoparticles. Typical TEM images of nanosize HAp particles produced through reactions 5 and 6 after being milled in both metallic and polymeric vials have been shown in Figure 5. 


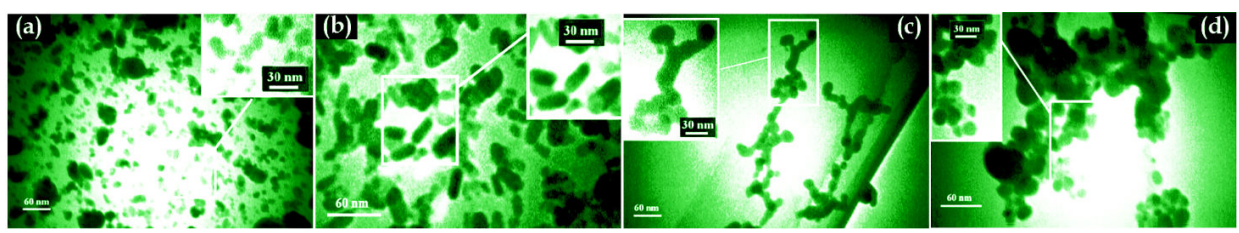

Figure 5. Morphologies of HAp synthesized through reactions 5 after being milled for $60 \mathrm{~h}$ in (a) metallic vials and (b) polymeric vials; through reactions 6 after being milled for $60 \mathrm{~h}$ in (c) metallic vials and (d) polymeric vials.

The results reveal that the single-crystal HAp nanoparticles have been successfully produced in metallic and polymeric vials through two different experimental procedures. Transmission electron microscopy images illustrate the wide morphology spectrums of the single-crystal HAp nanoparticles which are ellipse-, rod- and spherical-like morphologies each of which can be applied for specific purpose. After $60 \mathrm{~h}$ milling, this method results in the single-crystal HAp with their average sizes below 21 and $24 \mathrm{~nm}$ in the tempered chrome steel and polyamide- 6 vials, respectively. According to TEM images the obtained single-crystal HAp in polymeric vials have more production efficiency and better uniform geometry distribution than products in metallic vials. In metallic vial, intense agglomeration happens during mechanochemical process as shown in Figure 6. Therefore, an important conclusion reaches that the polyamide- 6 vial is more suitable than the tempered chrome steel vial for the synthesis of single-crystal HAp nanoparticles with appropriate morphology.
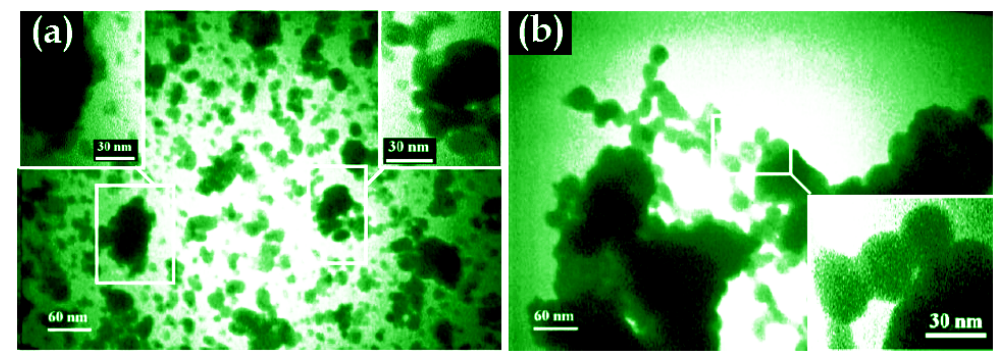

Figure 6. TEM images of agglomerated products which is obtained after $60 \mathrm{~h}$ milling in metallic vials through a (a) reaction 5 and (b) reaction 6 (Honarmandi et al., 2009).

\subsubsection{Milling atmosphere effect on structural features of hydroxyapatite}

In recent years, various mechanochemical processes were utilized to synthesis HAp nanostructures. For instance, Gergely et al. (Gergely et al., 2010) synthesized HAp by using recycled eggshell. The observed phases of the synthesized materials were dependent on the mechanochemical activation method (ball milling and attrition milling). Attrition milling proved to be more efficient than ball milling, as resulted nanosize, homogenous HAp even after milling. SEM micrographs showed that the ball milling process resulted in micrometer 
sized coagulated coarse grains with smooth surface, whereas attrition milled samples were characterized by the nanometer size grains. Wu et al. (Wu et al. 2011) synthesized HAp from oyster shell powders by ball milling and heat treatment. The wide availability and the low cost of oyster shells, along with their biological- natural origin are highly attractive properties in the preparation of HAp powders for biomedical application. Chemical and microstructural analysis has shown that oyster shells are predominantly composed of calcium carbonate with rare impurities. Solid state reactions between oyster shell powders (calcite polymorph of $\left.\mathrm{CaCO}_{3}\right)$ and calcium pyrophosphate $\left(\mathrm{Ca}_{2} \mathrm{P}_{2} \mathrm{O}_{7}\right)$ or dicalcium phosphate dihydrate $\left(\mathrm{CaHPO}_{4} \cdot 2 \mathrm{H}_{2} \mathrm{O}, \mathrm{DCPD}\right)$ were performed through ball milling and subsequently heat treatment. The ball milling and heat treatment of $\mathrm{Ca}_{2} \mathrm{P}_{2} \mathrm{O}_{7}$ and oyster shell powders in air atmosphere produced mainly HAp with a small quantity of $\beta$-TCP as a by product. However, oyster shell powder mixed with DCPD and milled for $5 \mathrm{~h}$ followed by heat-treatment at $1000 \mathrm{C}$ for $1 \mathrm{~h}$ resulted in pure HAp, retaining none of the original materials.
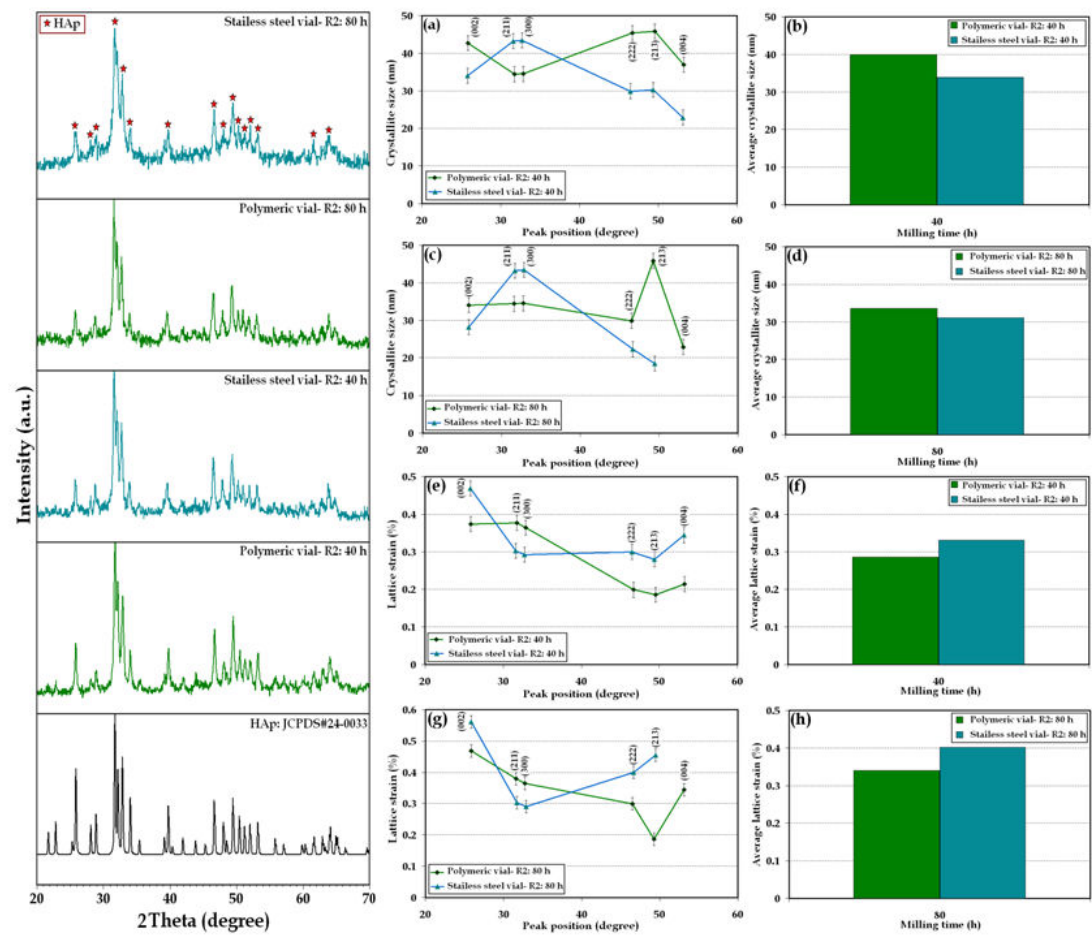

Figure 7. XRD patterns, crystallite size, lattice strain and their average of samples milled for 40 and $80 \mathrm{~h}$ in polymeric and metallic vials under argon atmosphere.

Mechanosynthesis of calcium phosphates can be performed under air or inert gas atmosphere. In most papers and patents, grinding under air atmosphere was selected. So far, only 
a few papers were devoted to mechanosynthesis of calcium phosphates under inert gas atmosphere (Nakano et al, 2001). To understand the effect of inert gas atmosphere, the mechanochemical synthesis under argon atmosphere was investigated by our research group. The starting reactant materials are $\mathrm{CaCO}_{3}$ and $\mathrm{CaHPO}_{4}$. The initial powders with the desired stoichiometric proportionality were mixed under a purified argon atmosphere (purity> 99.998 vol \%). Figure 7 shows the XRD patterns of the powder mixture after 40 and $80 \mathrm{~h}$ of milling in the polymeric and metallic vials under argon atmosphere. The XRD patterns of obtained powders exhibit that the production of mechanical activation is single phase HAp. Also, Figure 7 illustrates the determined amounts of crystallite size; lattice strain and their average for experimental outcomes after 40 and $80 \mathrm{~h}$ of milling in polymeric and metallic vials under argon atmosphere.
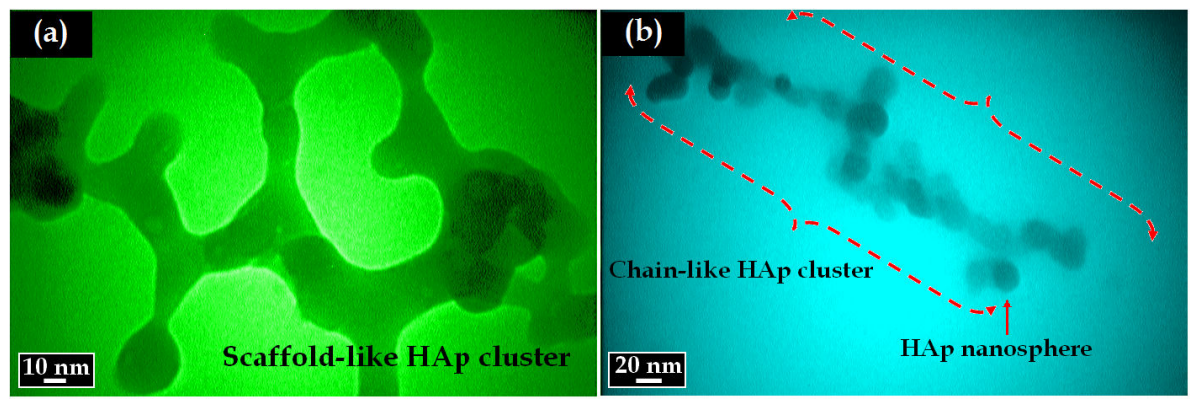

Figure 8. Typical TEM micrograph of nanocrystalline HAp after $80 \mathrm{~h}$ of milling under argon atmosphere in (a) polymeric and (b) metallic vials.
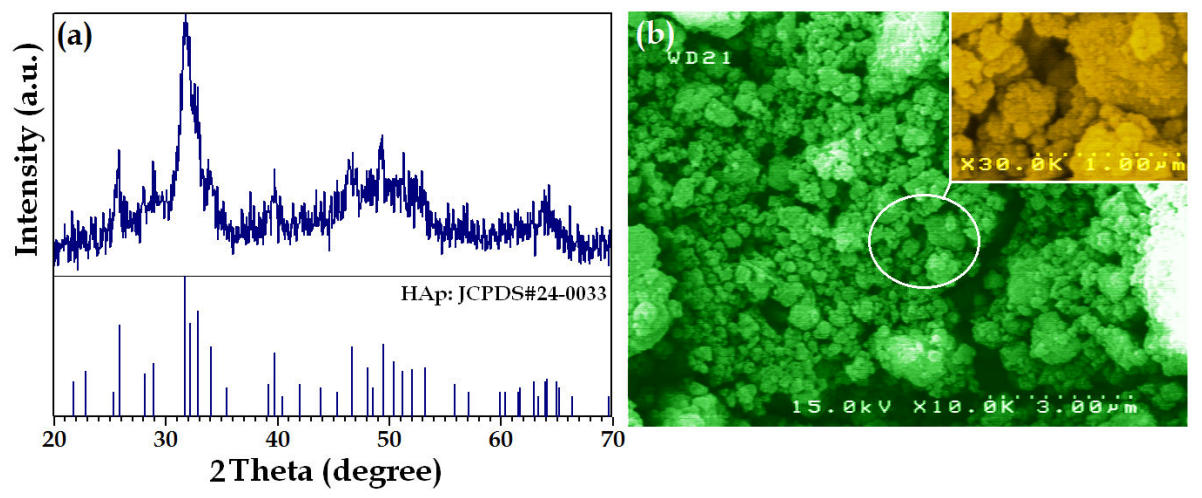

Figure 9. a) XRD profile and (b) FE-SEM images of nanocrystalline HAp with low degree of crystallinity after $2 \mathrm{~h}$ of milling in polymeric vial under air atmosphere.

Using the (0 02 2) plane (Figure 7a), the crystallite size of HAp is around 43 and $34 \mathrm{~nm}$ after $40 \mathrm{~h}$ of milling in polymeric and metallic vials, respectively. For comparison, the mean values de- 
termined from the use of six planes simultaneously, i.e. (0 0 2), (2 1 1), (3 0 0), (2 2 2), (2 13 ), and $(004)$ planes. The calculated data indicates that the average crystallite size of HAp is around 40 and $34 \mathrm{~nm}$, respectively. Moreover, using the $\left(\begin{array}{lll}0 & 0\end{array}\right)$ plane the crystallite size of HAp is around 34 and $28 \mathrm{~nm}$ after $80 \mathrm{~h}$ of milling in polymeric and metallic vials, respectively. However, the average crystallite size of HAp is around 34 and $31 \mathrm{~nm}$ after $80 \mathrm{~h}$ of milling in polymeric and metallic vials, respectively. The evaluation of the lattice strain of HAp reveals that the average of lattice strain partially increased from $0.286 \%$ to $0.340 \%$ after $80 \mathrm{~h}$ of milling in polymeric vial. A similar trend was observed in the average lattice strain of HAp after $80 \mathrm{~h}$ of milling. According to Figure 7 , the average crystallite size decreases and the average lattice strain increases with increase of milling time from 40 up to $80 \mathrm{~h}$. The TEM micrographs of synthesized powder after $80 \mathrm{~h}$ of milling in polymeric and metallic vials under argon atmosphere are shown in Figure 8. The TEM micrographs show that HAp particles can attach at crystallographically specific surfaces and form scaffold- and chain-like cluster composed of many primary nanospheres. In is found that (Pan et al., 2008) the living organisms build the outer surface of enamel by an oriented assembly of the rod-like crystal and such a biological construction can confer on enamel protections against erosion. It should be noted that, comparison of the physical, mechanical and biocompatibility between classical HAp ceramics and the novel nanostructures will be carried out in our laboratory.

Whilst the main advantages of the mechanochemical synthesis of ceramic powders are simplicity and low cost, the main disadvantages are the low crystallinity and calcium-deficient nonstoichiometry $(\mathrm{Ca} / \mathrm{P}$ molar ratio $1.50-1.64)$ of the HAp powders, as this results in their partial or total transformation into $\beta$-TCP during calcination (Bose et al., 2009). Hence, control over crystallinity degree of HAp nanostructures for specific applications is a challenging task. Based on experimental results, we conclude that the chemical composition of initial materials, milling time, milling media, and atmosphere are important parameters that affect the structural properties (crystallite size, lattice strain, crystallinity degree) and morphological features of HAp nanostructures during mechanochemical process. For example, mechanical activation of $\mathrm{Ca}(\mathrm{OH})_{2}$ and $\mathrm{P}_{2} \mathrm{O}_{5}$ powder mixture lead to the formation of single phase HAp with low fraction of crystallinity (Figure 9). According to this mechanochemical reaction (7), nanocrystalline HAp with an average crystallite size of about $14 \mathrm{~nm}$ was produced after $2 \mathrm{~h}$ of milling in polymeric vial under air atmosphere. In addition the fraction of crystallinity was around $7 \%$.

$$
10 \mathrm{Ca}(\mathrm{OH})_{2}+3 \mathrm{P}_{2} \mathrm{O}_{5} \rightarrow \mathrm{Ca}_{10}\left(\mathrm{PO}_{4}\right)_{6}(\mathrm{OH})_{2}+9 \mathrm{H}_{2} \mathrm{O}
$$

Figure $9 \mathrm{~b}$ shows the morphology and particle size distribution of the nanocrystalline HAp produced after $2 \mathrm{~h}$ of milling. From the FE-SEM micrograph, it is clear that the powders displayed an agglomerate structure which consisted of several small particles with the average size of about $58 \mathrm{~nm}$. In the field of science and technology of particles, agglomerate size is one of the key factors that influence the densification behaviors of nanoparticles. Large particle size along with hard agglomerates shows lower densification in calcium phosphate ceramics due to the formation of large interagglomerate/intraagglomerate pores (Banerjee et 
al., 2007). The large interagglomerate/intraagglomerate pores increase the diffusion distance, resulting in lowering the densification rate. Thus, to compensate for this, higher sintering temperature becomes necessary.

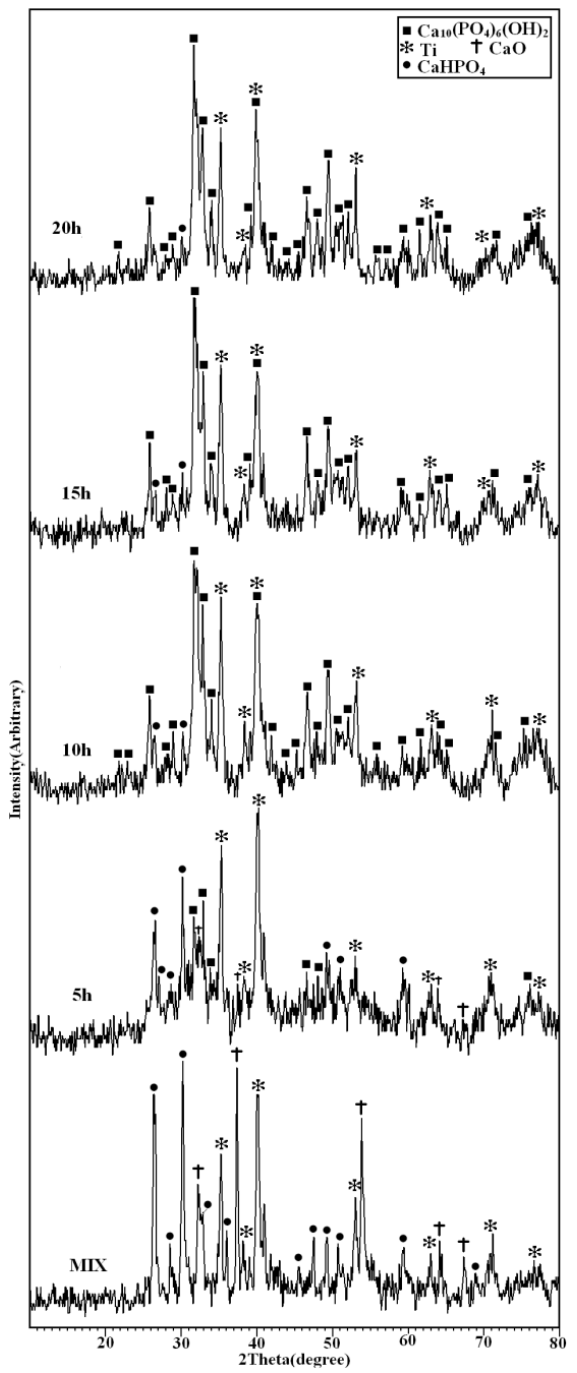

Figure 10. XRD patterns of the HAp-20\%wt Ti nanocomposite after mechanochemical process for various time periods (Fahami et al., 2011). 

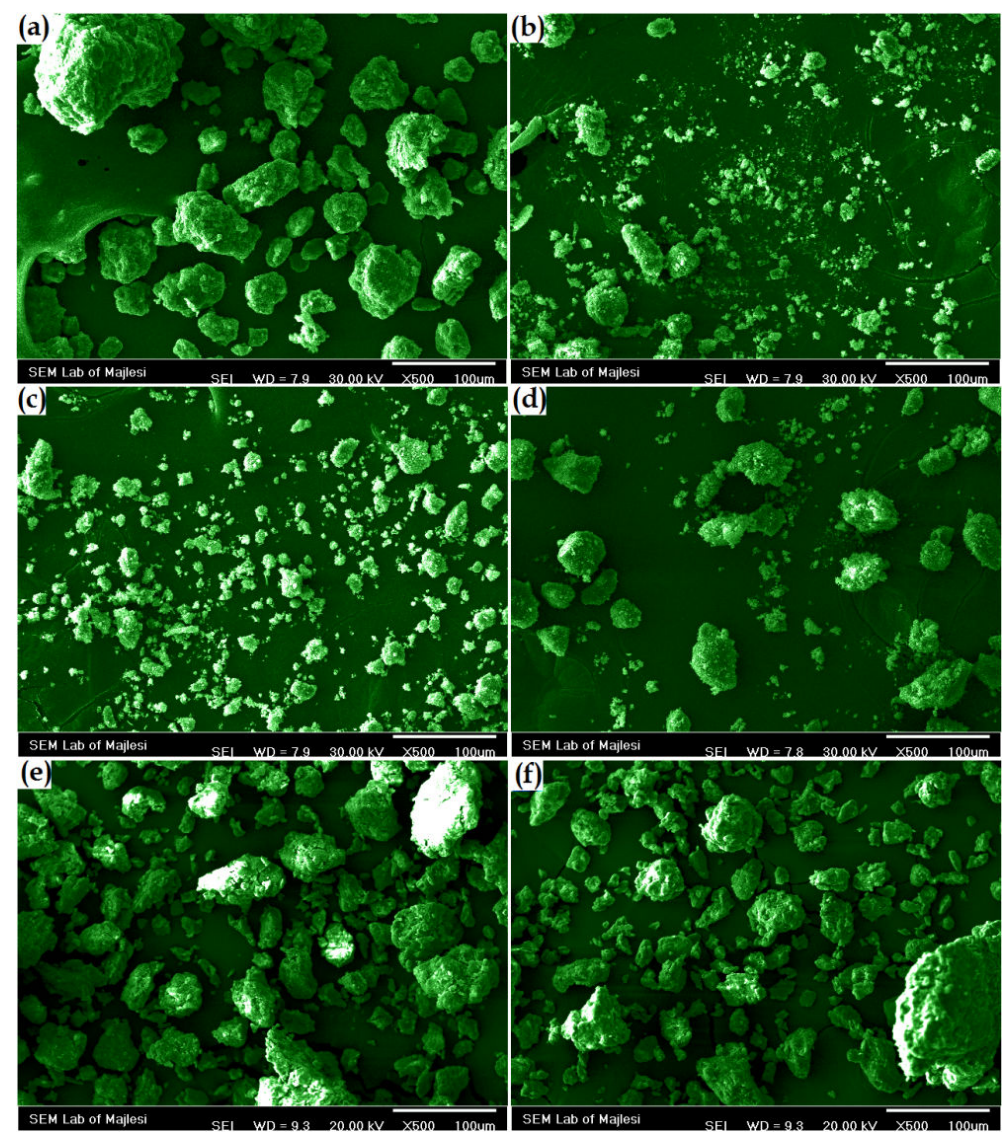

Figure 11. SEM micrographs of the HAp-20 wt.\% Ti nanocomposite after different milling times (a) 5, (b) 10, (c) 15, (d) 20, (e) 40 , and (f) $50 \mathrm{~h}$.

\subsubsection{Hydroxyapatiteltitanium (HAp-Ti) nanocomposite}

Apart from the displacement reactions to reduce oxides, chlorides, and sulfides to pure metals, mechanical alloying technique was also used to synthesize a large number of commercially important alloys, compounds, and nanocomposites using the mechanochemical reactions (Suryanarayana, 2001; De Castro \& Mitchell, 2002; Balaz, 2008). An important characteristic of mechanosynthesized composites is that they have nanocrystalline structures which could improve the mechanical as well as biological properties (Silva et al., 2007). Nowadays, ceramic nanocomposites which play a crucial role in technology can be synthesized using surprisingly simple and inexpensive techniques such as a mechanochemical method which ordinarily include a two step process. Considering the above characteristics of the ceramic-based compo- 
sites, the possibility of using one step mechanochemical process as a simple, efficient, and inexpensive method to prepare HAp-20wt.\% Ti nanocomposite was investigated by our research group (Fahami et al., 2011). Furthermore, crystallite size, lattice strain, crystallinity degree, and morphological properties of products were determined due to the biological behaviour of HAp ceramics depends on structural and morphological features. For the preparation of HAp-20 wt.\% Ti nanocomposite, anhydrous calcium hydrogen phosphate and calcium oxide mixture with $\mathrm{Ca} / \mathrm{P}=1.67$ ratio was milled with the distinct amount of elemental titanium (20 wt.\%) during 0, 5, 10, 15, and $20 \mathrm{~h}$ by a high energy planetary ball mill under highly purified argon gas atmosphere. The following reaction can be occurred at this condition (8):

$$
6 \mathrm{CaHPO}_{4}+4 \mathrm{CaO}+\mathrm{Ti} \rightarrow \mathrm{Ca}_{10}\left(\mathrm{PO}_{4}\right)_{6}(\mathrm{OH})_{2}+\mathrm{Ti}+2 \mathrm{H}_{2} \mathrm{O}
$$

Figure 10 shows the XRD patterns of the samples after mechanochemical process for various time periods. At the initial mixture, only sharp characteristic peaks of $\mathrm{CaHPO}_{4}, \mathrm{CaO}$ and Ti are observed. With increasing milling time to $5 \mathrm{~h}$, the sharp peaks of starting materials degraded significantly, but the decreasing rate of each initial powder was differed. On the other hand, the appearance of weak peak between 31 and 32 confirms the formation of HAp phase. The main products of powder mixtures after $10 \mathrm{~h}$ of milling were HAp and Ti. The XRD patterns of the samples which are milled for 15 and $20 \mathrm{~h}$ indicate that increasing milling time to above $10 \mathrm{~h}$ does not accompany with any phase transformation. The determined amounts of crystallite size and lattice strain of the samples, after different milling time were presented in Table 1 . According to Table 1 , the crystallite size of HAp decrease with increasing milling time up to $20 \mathrm{~h}$; whereas the change in crystallite size of Ti with increasing milling time is not linear. The calculated amount of crystallinity degree indicate that the increasing milling time dose not accompany by remarkable change in degree of crystallinity. Since the amorphous powders could find applications to promote osseointegration or as a coating to promote bone ingrowth into prosthetic implants (Sanosh et al., 2009), the resultant powders could be used to various biomedical applications.

\begin{tabular}{ccccccc}
\hline Samples & Milling time (h) & \multicolumn{2}{c}{ Crystallite size (nm) } & \multicolumn{2}{l}{ Lattice strain (\%) } & Crystallinity (\%) \\
\hline I & HAp & Ti & HAp & Ti & - \\
\hline II & 5 & - & 22.8 & - & 0.494 & 17 \\
\hline III & 10 & 20.13 & 18.7 & 0.492 & 0.621 & 15 \\
\hline IV & 15 & 19.06 & 19.3 & 0.522 & 0.601 & 13 \\
\hline
\end{tabular}

Table 1. Comparison between structural features of the samples after different milling times. 
The SEM micrographs of the samples after different milling times are presented in Figure 11. It can be seen that the particles of products can be attached together at specific surfaces and form elongated agglomerates which composed of many primary crystallites. The agglomerates with flaky-like structure formed after $10 \mathrm{~h}$ of milling. It seems that the existence of ductile $\mathrm{Ti}$ can be led to the more agglomeration during mechanochemical process. With increasing milling time to $20 \mathrm{~h}$ owing to sever mechanical deformation introduced into the powder, particle, and crystal refinement have occurred. Based on SEM observations, milling process reached steady state after $40 \mathrm{~h}$ of milling where the particles have become homogenized in size and shape. Figure 12 shows the SEM images of the HAp-20wt.\% Ti nanocomposite after 40 and $50 \mathrm{~h}$ of milling and subsequent heat treatment at $700 \mathrm{C}$ for $2 \mathrm{~h}$. According to SEM observations, the annealing of the milled samples at $700 \mathrm{C}$ demonstrates the occurrence of grain growth.
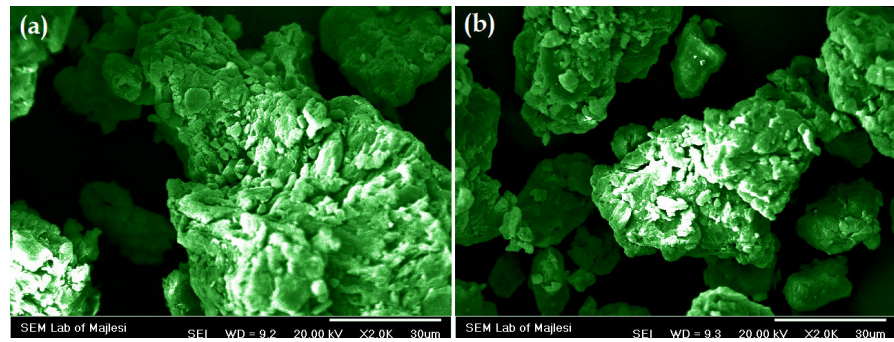

Figure 12. SEM micrographs of the HAp-20 wt.\% Ti nanocomposite after different milling times (a) 40 and (b) $50 \mathrm{~h}$ and subsequent heat treatment at $700 \mathrm{C}$ for $2 \mathrm{~h}$.

\subsubsection{Hydroxyapatite/geikielite $\left(\mathrm{HAp} / \mathrm{MgTiO}_{3}-\mathrm{MgO}\right)$ nanocomposite}

In the field of nanocomposites, an ideal reinforcing material for calcium phosphate-based composites has not yet been found. Nevertheless, different approaches have been extensively investigated in order to develop calcium phosphate-based composites. Despite a large number of studies on the synthesis of HAp and TCP composites (Viswanath \& Ravishankar, 2006; Rao \& Kannan, 2002; Nath et al., 2009; Jin. et al., 2010; Cao \& Kuboyama, 2010; Hu et al., 2010), no systematic investigations on the preparation of $\mathrm{HAp} / \mathrm{MgTiO}_{3}-\mathrm{MgO}$ are performed. Therefore, a novel approach to synthesis of $\mathrm{HAp} / \mathrm{MgTiO}_{3}-\mathrm{MgO}$ nanocomposite has developed by our research group (Fahami et al., 2012). In this procedure, the starting reactant materials are $\mathrm{CaHPO}_{4}, \mathrm{CaO}$, titanium dioxide $\left(\mathrm{TiO}_{2}\right)$, and elemental magnesium $(\mathrm{Mg})$. Synthesis of $\mathrm{HAp} / \mathrm{MgTiO}_{3}-\mathrm{MgO}$ composite nanopowders consists of: (i) mechanical activation of powder mixture, and (ii) subsequently thermal treatment at $700 \mathrm{C}$ for $2 \mathrm{~h}$. The obtained mixture was milled in a high energy planetary ball mill for $10 \mathrm{~h}$ according to the following reaction.

$$
6 \mathrm{CaHPO}_{4}+4 \mathrm{CaO}+\mathrm{TiO}_{2}+2 \mathrm{Mg} \rightarrow \mathrm{Ca}_{10}\left(\mathrm{PO}_{4}\right)_{6}(\mathrm{OH})_{2}+\mathrm{TiO}_{2}+2 \mathrm{MgO}+2 \mathrm{H}_{2} \uparrow
$$




$$
\begin{aligned}
& \mathrm{MgO}+\mathrm{TiO}_{2} \rightarrow \mathrm{MgTiO}_{3} \\
& \Delta \mathrm{G}_{298 \mathrm{~K}}=-25.410 \mathrm{~kJ}, \Delta \mathrm{H}_{298 \mathrm{~K}}=-26.209 \mathrm{~kJ}
\end{aligned}
$$

Figure 13 shows the XRD profiles of the $\mathrm{CaHPO}_{4}, \mathrm{CaO}, \mathrm{TiO}_{2}$, and $\mathrm{Mg}$ powder mixture after $10 \mathrm{~h}$ of milling and after thermal annealing at $700 \mathrm{C}$ for $2 \mathrm{~h}$. As can be seen, the product of mechanochemical process in presence of $20 \mathrm{wt} . \%\left(\mathrm{TiO}_{2}, \mathrm{Mg}\right)$ is $\mathrm{HAp} / \mathrm{MgO}-\mathrm{TiO}_{2}$ composite. From Figure $13 \mathrm{~b}$, it was verified the existence of $\mathrm{HAp}$ and geikielite $\left(\mathrm{MgTiO}_{3}\right)$ phases together with minor $\mathrm{MgO}$ phase after the annealing at $700{ }^{\circ} \mathrm{C}$. This suggest that the thermal treatment at $700{ }^{\circ} \mathrm{C}$ led to the formation of $\mathrm{MgTiO}_{3}$ by the following reaction:

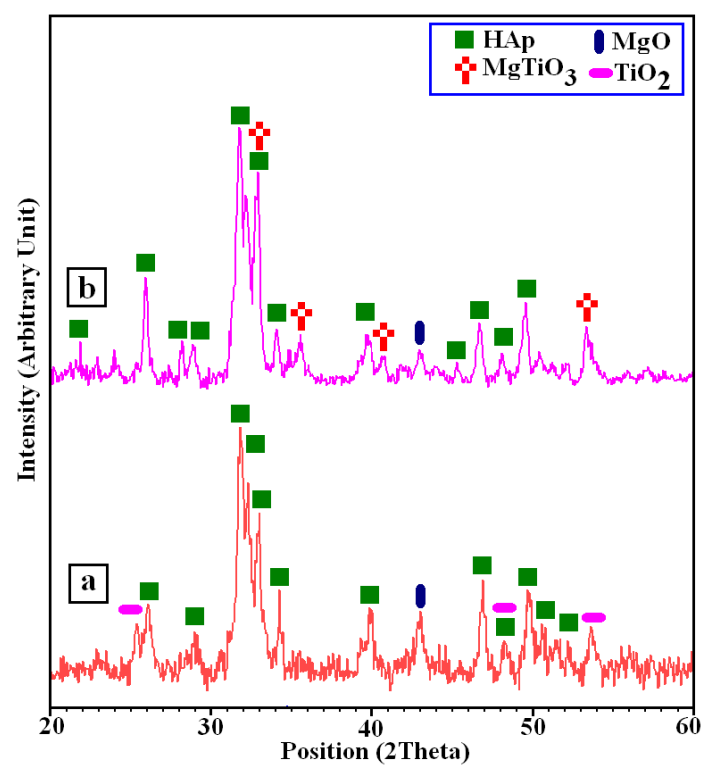

Figure 13. XRD patterns of the samples: (a) $\mathrm{HAp} / \mathrm{MgO}-\mathrm{TiO}_{2}$ after $10 \mathrm{~h}$ of milling, and (b) $\mathrm{HAp} / \mathrm{MgTiO}_{3}-\mathrm{MgO}$ after 10 h of milling + heat treatment at $700^{\circ} \mathrm{C}$ (Fahami et al., 2012).

Figure 14 shows the SEM micrographs and EDX results of the samples after milling and thermal treatment. As can be seen in Figure 15a, a very fine structure was formed after $10 \mathrm{~h}$ of milling. After thermal treatment at $700^{\circ} \mathrm{C}$ (Figure 14c), continuous evolution of the morphological features was appeared. The mean size of the powder particles increased after thermal treatment; however, only a slight change in particle size was observed in heat treated sample at 700 ${ }^{\circ} \mathrm{C}$ compare to the milled powder. After milling and subsequent thermal treatment at $700^{\circ} \mathrm{C}$, the products were composed of fine particles with a mean particle size of about 482 and $510 \mathrm{~nm}$, respectively. Figures $14 \mathrm{~b}$ and d represent the EDX results for HAp-based composites which are synthesized after $10 \mathrm{~h}$ of milling and subsequent heat treatment at $700{ }^{\circ} \mathrm{C}$. EDX data show that the main elements of the calcium phosphate-based composite nanopowders are calcium, phos- 
phorus, oxygen, magnesium, and titanium. The EDX of HAp crystal, present in the HAp/MgO $-\mathrm{TiO}_{2}$ composite exhibit a molar ratio $\mathrm{Ca} / \mathrm{P}=1.93$, whereas in the $\mathrm{HAp} / \mathrm{MgTiO}_{3}-\mathrm{MgO}$ composite the molar ratio of calcium to phosphorus is greater $(\mathrm{Ca} / \mathrm{P}=2.87)$. These results suggest that the HAp crystals are closer to the expected value for the molar ratio of calcium to phosphorus ratio for the standard HAp (Ca/P = 1.67) (Cacciotti et al., 2009) and commercial HAp (2.38) (Silva et al., 2002), respectively. It is noteworthy to mention that chemically stable contaminants were not detected due to the excessive adhesion of powders to the vial and balls. Figure $15 \mathrm{dem}$ onstrates the TEM images of the $\mathrm{HAp} / \mathrm{MgTiO}_{3}-\mathrm{MgO}$ composite nanopowders produced after $10 \mathrm{~h}$ of milling and subsequent annealing at $700^{\circ} \mathrm{C}$ for $2 \mathrm{~h}$. As can be seen, the agglomerates with mean size of about $322 \mathrm{~nm}$ were developed after thermal treatment at $700^{\circ} \mathrm{C}$. In this sample, the cluster-like shape particles were composed of fine spheroidal shape crystals with a mean size of about $55 \mathrm{~nm}$. It should be mentioned that chemical interactions at the contacting surface of crystals resulted incluster-like shape aggregates which were composed of fine spheroidal shapecrystals. This phenomenon is referred to the nature of milling process which originates through repeated welding, fracturing and re-welding of fine powder particles (Suryanarayana, 2001; De Castro \& Mitchell, 2002). It is found that MgO-doped HAp/TCP ceramics present high density and significantly enhance mechanical properties without any phase transformation of $\beta$-TCP to $\alpha$-TCP up to $1300^{\circ} \mathrm{C}$ (Farzadi et al., 2011). Moreover, a patent (Sul, 2008) reported the biocompatibility and osteoconductivity of magnesium titanate oxide film implant for utilizing in several medical fields such as dentistry, orthopedic, maxillofacial, and plastic surgery. Therefore, the presence of $\mathrm{MgO}$ and $\mathrm{MgTiO}_{3}$ phases along with HAp in outputs can be enhanced the biological and mechanical properties of HAp-based bioceramics.

\subsection{Mechanochemical synthesize of fluorapatite nanostructures}

The inorganic matrix of the bone is based on HAp doped with different quantities of cations, such as $\mathrm{Na}^{+}, \mathrm{K}^{+}$and $\mathrm{Mg}^{2+}$, and anions, such as $\mathrm{CO}_{3}{ }^{2-}, \mathrm{SO}_{4}{ }^{2-}$ and $\mathrm{F}^{-}$. Among them, $\mathrm{F}^{-}$plays a leading role because of its influence on the physical and biological characteristics of HAp (Nikcevic et al., 2004). In the recent years, fluoridated HAp (FHAp and FAp) has attracted much attention as a promising material to replace HAp in biomedical applications (Kim et al., 2004a; Fathi \& Mohammadi Zahrani, 2009). It is found that the incorporation of fluoride ions into the HAp structure considerably increases the resistance of HAp to biodegradation and thermal decomposition (Fathi et al., 2009). In addition, fluoridated hydroxyapatite could provide better protein adsorption (Zeng et al., 1999) and comparable or better cell attachment than HAp (Kim et al., 2004b). This substitution also has positive effects on proliferation, morphology and differentiation of osteoblastic-like cells and promotes the bioactivity (Fathi et al., 2009). For all these reasons, synthesis of FHAp and FAp is of great value and has been widely investigated by multiple techniques, such as precipitation (Chen \& Miao, 2005), sol-gel (Cheng et al., 2006), hydrolysis (Kurmaev et al., 2002), hydrothermal (Sun et al., 2012), and mechanochemical methods (Nikcevic et al., 2004). 

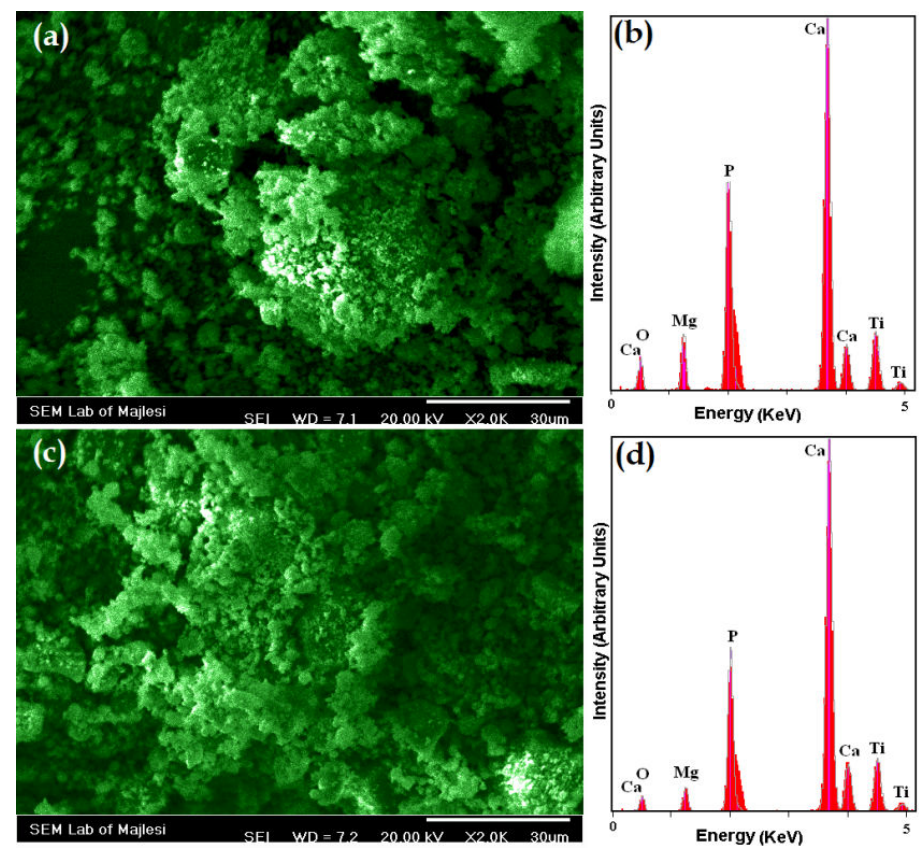

Figure 14. SEM micrographs and EDX results of the samples: (a-b) $\mathrm{HAp} / \mathrm{MgO}-\mathrm{TiO}_{2}$ after $10 \mathrm{~h}$ of milling, (c-d) $\mathrm{HAp} /$ $\mathrm{MgTiO}_{3}-\mathrm{MgO}$ after $10 \mathrm{~h}$ of milling + heat treatment at $700{ }^{\circ} \mathrm{C}$ for $2 \mathrm{~h}$.

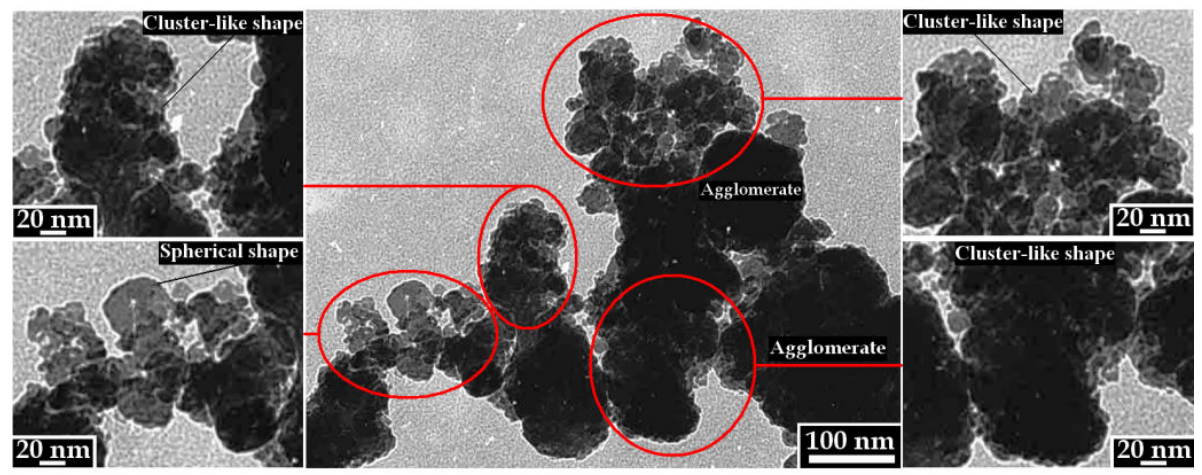

Figure 15. TEM images of the $\mathrm{HAp} / \mathrm{M}_{\mathrm{g}} \mathrm{TiO}_{3}-\mathrm{MgO}$ composite nanopowders after $10 \mathrm{~h}$ of milling + heat treatment at $700^{\circ} \mathrm{C}$ for $2 \mathrm{~h}$ (Fahami et al., 2012).

Nikcevic et al. (Nikcevic et al., 2004) synthesized nanostructured fluorapatite/fluorhydroxyapatite and carbonated fluorapatite/fluorhydroxyapatite by mechanochemical process. Powder mixture of $\mathrm{Ca}(\mathrm{OH})_{2}-\mathrm{P}_{2} \mathrm{O}_{5}-\mathrm{CaF}_{2}$ were milled in planetary ball mill. A carbonated fluo- 
rhydroxyapatite, FHAp was formed after $5 \mathrm{~h}$ of milling and carbonated fluoroapatite was formed after $9 \mathrm{~h}$ of milling. Complete transformation of the carbonated form of FAp into the single phase of FAp occurred after $9 \mathrm{~h}$ milling and thermally treating. After that, Zhang et al. (Zhang et al., 2005) synthesized FHAp from the starting materials of $\mathrm{CaCO}_{3}$, $\mathrm{CaH}$ $\mathrm{PO}_{4} \cdot 2 \mathrm{H}_{2} \mathrm{O}$, and $\mathrm{CaF}_{2}$ via a mechanochemical-hydrothermal route. The mechanism study revealed that under such mechanochemical-hydrothermal conditions the formation reactions of FHAp were completed in two stages. The starting materials firstly reacted into a poorly crystallized calcium-deficient apatite and the complete incorporation of fluoride ions into apatite occurred in the second stage.

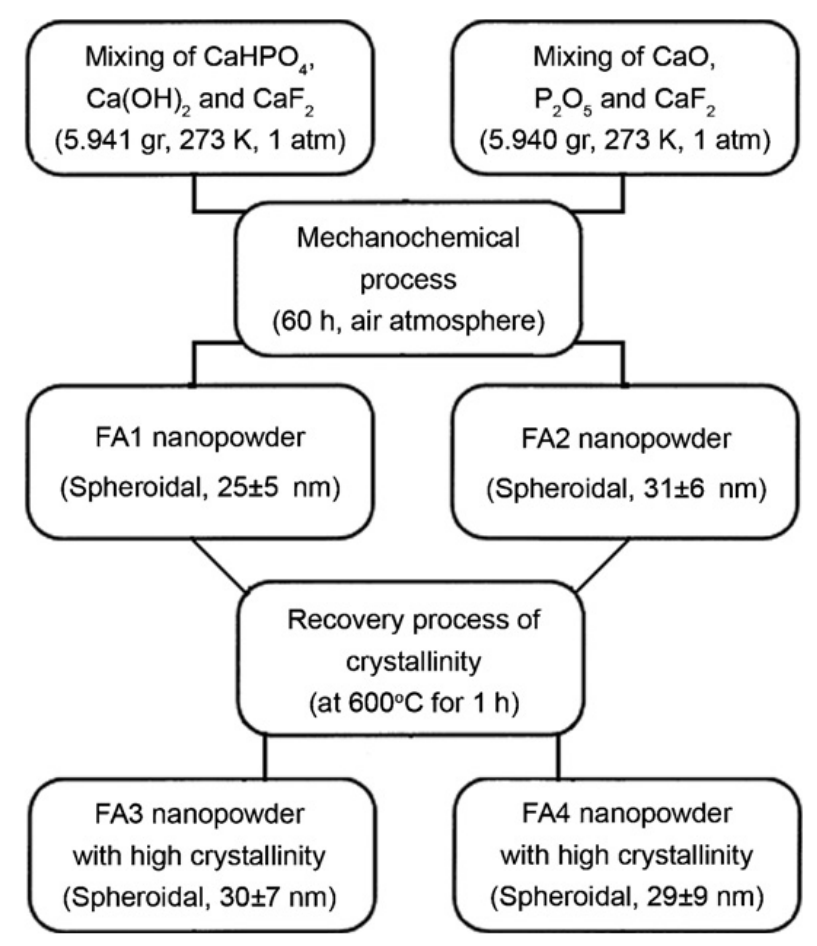

Figure 16. Flow sheet of FAp nanoparticles preparation (Ebrahimi-Kahrizsangi et al., 2011).

\subsubsection{Single-crystal fluorapatite nanoparticles}

Along with the development of mechanochemical processes, Mohammadi Zahrani \& Fathi (Mohammadi Zahrani \& Fathi, 2009) evaluated the effect of ball milling parameters on the synthesis of FAp nanopowder; also, the effect of fluoridation on bioresorbability and bioactivity of apatite was studied. Fluoridated hydroxyapatite nanopowders with $100 \%$ (FAp) were synthesized via mechanical alloying method. The results showed that the size and number of balls had no significant effect on the synthesizing time and grain size of FAp, 
while decreasing the rotation speed or ball to powder weight ratio increased synthesizing time and the grain size of FAp. In vitro test indicated that the bioactivity of FAp was less than HAp since the dissolution rate, precipitation amount and the size of precipitated bonelike apatite crystals on the surface of FAp samples was clearly lower than HAp (Nikcevic et al., 2004; Zhang et al., 2005). Recently, Ebrahimi-Kahrizsangi et al. (Ebrahimi-Kahrizsangi et al., 2011) synthesized FAp nanostructures from the starting materials of $\mathrm{CaHPO}_{4}, \mathrm{Ca}(\mathrm{OH})_{2}$, $\mathrm{CaO}, \mathrm{P}_{2} \mathrm{O}_{5}$ and $\mathrm{CaF}_{2}$ via mechanochemical process. The suitability of using the mechanochemical process to prepare a high crystalline phase of FAp was studied. FAp nanopowders with different structural characteristics synthesized through novel dry mechanochemical processes, which are presented in Figure 16.
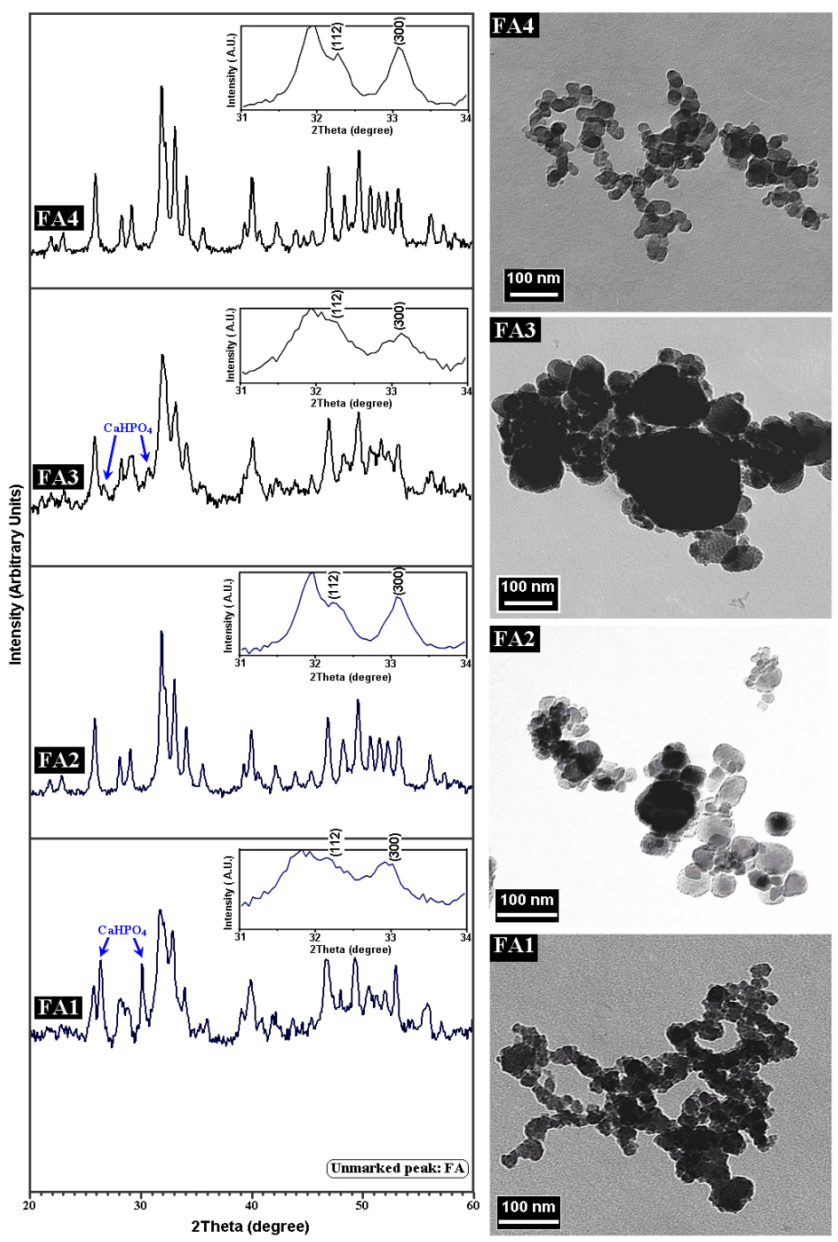

Figure 17. XRD patterns and morphological features of the FAp nanostructures (Ebrahimi-Kahrizsangi et al., 2011). 
The purpose of the milling was twofold: first, to activate the following reactions via mechanochemical processes, and second, to produce the nanostructured FAp.

$$
\begin{gathered}
6 \mathrm{CaHPO}_{4}+3 \mathrm{Ca}(\mathrm{OH})_{2}+\mathrm{CaF}_{2} \rightarrow \mathrm{Ca}_{10}\left(\mathrm{PO}_{4}\right)_{6} \mathrm{~F}_{2}+6 \mathrm{H}_{2} \mathrm{O} \\
9 \mathrm{CaO}+3 \mathrm{P}_{2} \mathrm{O}_{5}+\mathrm{CaF}_{2} \rightarrow \mathrm{Ca}_{10}\left(\mathrm{PO}_{4}\right)_{6} \mathrm{~F}_{2}
\end{gathered}
$$
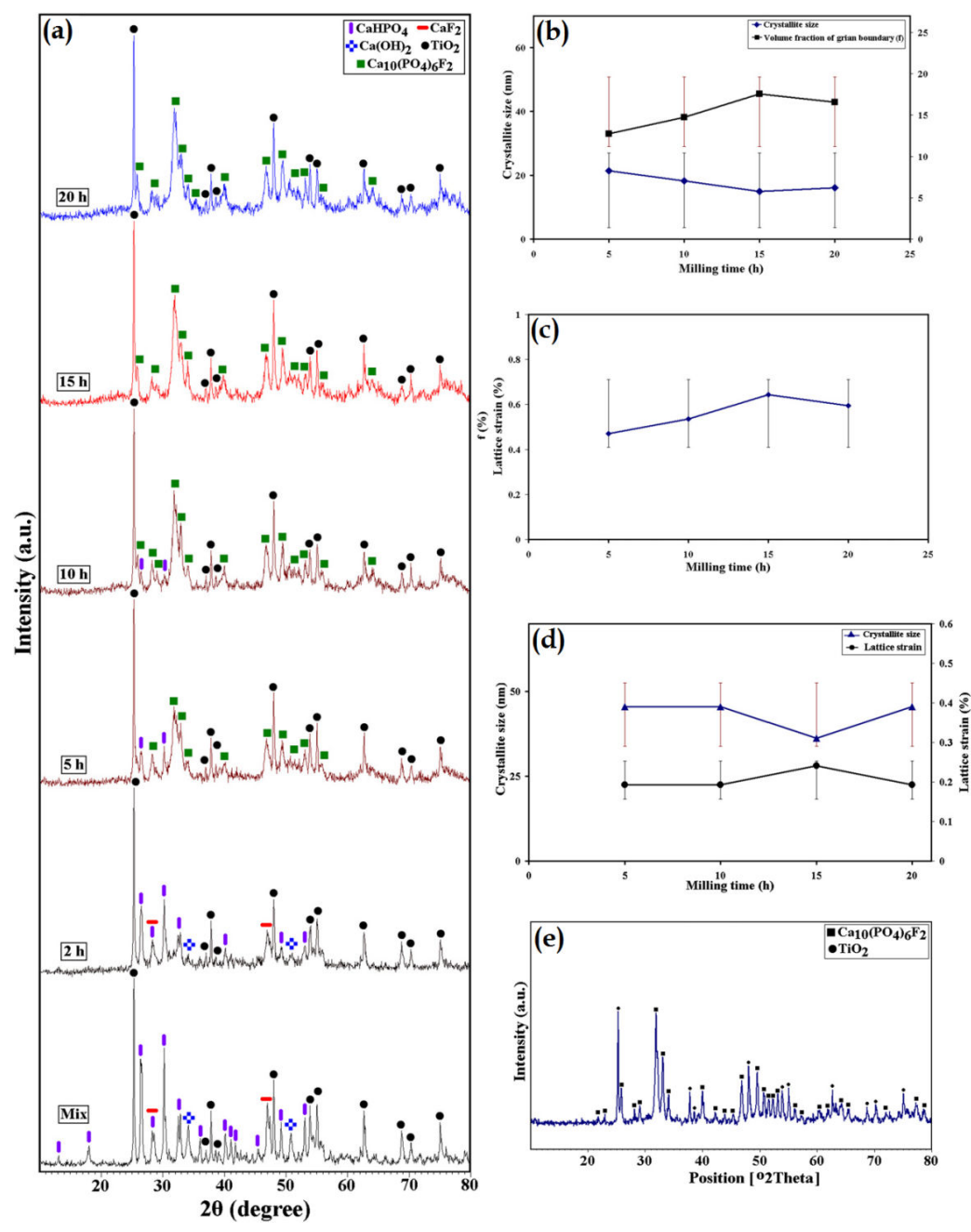

Figure 18. a) XRD patterns, and (b-d) structural features of $\mathrm{CaHPO}_{4}-\mathrm{Ca}(\mathrm{OH})_{2}-\mathrm{CaF}_{2}-\mathrm{TiO}_{2}$ powder mixture, mechanically alloyed for 2-20 h. (e) XRD profile of the $\mathrm{FAp}-\mathrm{TiO}_{2}$ nanocomposite after heat treatment at $650 \mathrm{C}$ (Ebrahimi-Kahrizsangi et al., 2011). 
Figure 17 illustrates XRD patterns and morphological features of the FAp nanostructures. XRD patterns of the FA1 and FA2 samples showing that the powders synthesized through the two different mechanochemical processes are mostly FAp. Complete agreement with the standard card of fluorapatite (JCPDS \#15-0876) was not observed for FA1 due to the presence of additional peaks at $2 \theta=26.59 \circ$ and $30.19 \circ$. These additional peaks were attributed to $\mathrm{CaHPO}_{4}$ from the starting materials. In FA2, complete agreement with JCPDS \#15-0876 was observed, allowing FA2 to be used as the pure FAp phase sample when required. The results from the structural studies indicate that the maximum lattice disturbance in the apatite structure after the mechanochemical process was at the $\left(\begin{array}{ll}0 & 0\end{array}\right)$ plane. According to TEM images, the FA1 particles are spheroidal with an average diameter of $25 \pm 5 \mathrm{~nm}$. However, it should be noted that the particles do not possess high regularity in shape; in other words, their surfaces are not smooth. The particles show a high tendency towards agglomeration. In addition, the sample FA2 possesses a mostly spherical structure with an average diameter of $31 \pm 6 \mathrm{~nm}$. The TEM image of the FA3 sample confirms that the particles are spheroidal with an average diameter of $30 \pm 7$ nm. As shown in Figure 17, the TEM image of sample FA4 shows the particles to be more spherical than the unheated FA2 particles, and the average size of the particles is $29 \pm 9 \mathrm{~nm}$. Based on the obtained data, the maximum particle size measured with TEM is below the crystallite size calculated from the line broadening of the X-ray diffraction peak. Thus we concluded that, after $60 \mathrm{~h}$ of milling and subsequent thermal treatment at $600 \mathrm{C}$, this method gives rise to single-crystal FAp with average sizes of 30, 37, 37 and $38 \mathrm{~nm}$ for FA1, FA2, FA3 and FA4, respectively. In most reports concerning the synthesis of FAp, the particle shapes are plates (Rameshbabu et al., 2006) or polyhedral (Barinov et al., 2004; Fathi \& Mohammadi Zahrani, 2009 ), but nanoparticles with spheroidal morphology were successfully prepared by current approach. Because the spherical geometry rather than irregular shape is important for achieving osseointegration (Hsu et al., 2007; Nayar et al., 2006), the products synthesized via mechanochemical processes are preferred for medical applications.

\subsubsection{Fluorapatite-titania $\left(\mathrm{FAp}-\mathrm{TiO}_{2}\right)$ nanocomposite}

As a fact that the incorporation of bioinert ceramics into calcium phosphate-based materials has demonstrated significant improvement in mechanical properties without substantial compromise in biocompatibility, some attempts have been made to develop FHAp-based composites such as: $\mathrm{FHAp}-\mathrm{Al}_{2} \mathrm{O}_{3}$ (Adolfsson et al., 1999), and $\mathrm{FHAp}-\mathrm{ZrO}_{2}$ (Kim et al., 2003; Ben Ayed \& Bouaziz, 2008) composites. However, only a few studies have been devoted to the use of solid state reaction in order to prepare FAp nanocomposites (Bouslama et al., 2009). Therefore, synthesis of $\mathrm{FAp}-\mathrm{TiO}_{2}$ nanocomposite which can present advantages of both $\mathrm{TiO}_{2}$ and FAp were carried out by Ebrahimi-Kahrizsangi et al. (Ebrahimi-Kahrizsangi et al., 2011). Based on XRD patterns and FT-IR spectroscopy, correlation between the structural features of the nanostructured $\mathrm{FAp}-\mathrm{TiO}_{2}$ and the process conditions was investigated. The starting reactant materials are $\mathrm{CaHPO}_{4}, \mathrm{Ca}(\mathrm{OH})_{2}, \mathrm{CaF}_{2}$, and $\mathrm{TiO}_{2}$. In the production of 
the nanocomposite, a distinct amount of titanium dioxide (20 wt.\%) was mixed with CaH$\mathrm{PO}_{4}, \mathrm{Ca}(\mathrm{OH})_{2}$ and $\mathrm{CaF}_{2}$ according to reaction (13), and were milled in planetary ball mill for $2,5,10,15$, and $20 \mathrm{~h}$ under ambient air atmosphere. The aims of the milling were twofold: the first one was to activate the following reaction via one step mechanochemical process, and the secondly, was to produce the $\mathrm{FAp}-\mathrm{TiO}_{2}$ nanocomposite.

$$
6 \mathrm{CaHPO}_{4}+3 \mathrm{Ca}(\mathrm{OH})_{2}+\mathrm{CaF}_{2}+\mathrm{TiO}_{2} \rightarrow \mathrm{Ca}_{10}\left(\mathrm{PO}_{4}\right)_{6} \mathrm{~F}_{2}+\mathrm{TiO}_{2}+6 \mathrm{H}_{2} \mathrm{O}
$$

Figure 18a shows the XRD patterns of $\mathrm{CaHPO}_{4}-\mathrm{Ca}(\mathrm{OH})_{2}-\mathrm{CaF}_{2}-\mathrm{TiO}_{2}$ powder mixture, mechanically alloyed for 2-20 h. An XRD pattern of the mixture before milling is given in the same figure for comparison. For the powder mixture, milled for $2 \mathrm{~h}$, all the sharp peaks corresponding to $\mathrm{Ca}(\mathrm{OH})_{2}, \mathrm{CaF}_{2}$ have diminished, and those corresponding to $\mathrm{CaHPO}_{4}$ have been broadened, indicating that a significant refinement in crystallite and particle sizes of the starting powders had occurred together with a degree of amorphization at the initial stage of mechanical activation. Also, the X-ray pattern of the sample, milled for $2 \mathrm{~h}$, shows the most intense peaks for $\mathrm{TiO}_{2}$. Upon $5 \mathrm{~h}$ of mechanical activation, several new broadened peaks especially between $2 \theta=31-34$ appear to emerge, corresponding to FAp phase. This suggests that nanocrystalline FAp phase has been formed as a result of mechanical activation. According to XRD profile, the main products of mechanochemical process after $5 \mathrm{~h}$ of milling were $\mathrm{FAp}$ and $\mathrm{TiO}_{2}$. Also, the two minor peaks observed in XRD patterns correspond to $\mathrm{CaHPO}_{4}$. When the mechanical activation time is extended to $15 \mathrm{~h}$, all the peaks corresponding to $\mathrm{CaHPO}_{4}$ have disappeared and only those belonging to $\mathrm{FAp}$ and $\mathrm{TiO}_{2}$ are detectable.
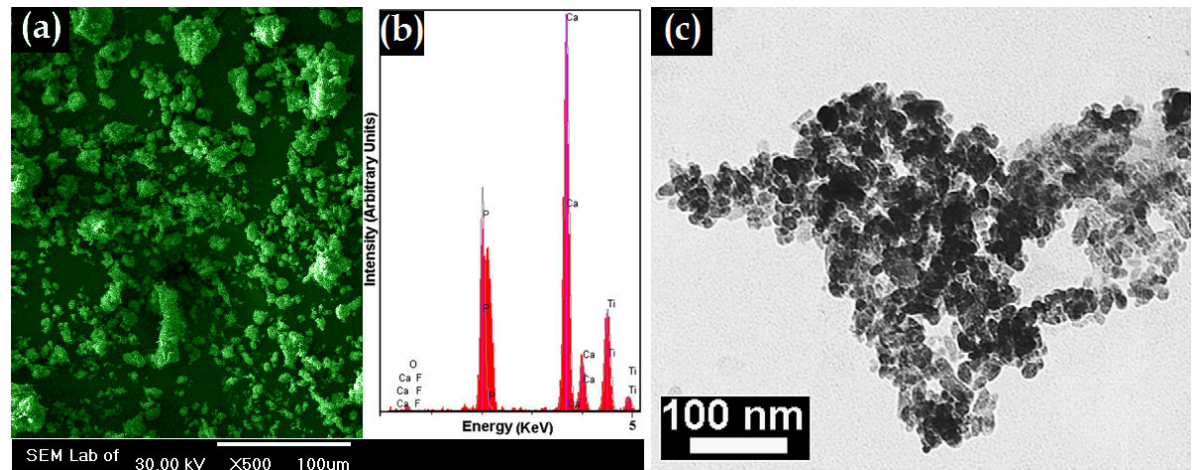

Figure 19. SEM micrograph and TEM image of $\mathrm{FAp}-\mathrm{TiO}_{2}$ nanocomposite after $20 \mathrm{~h}$ of milling (Ebrahimi-Kahrizsangi et al., 2011).

Figures $18 \mathrm{~b}$ and $\mathrm{c}$ show the variations of the crystallite size, lattice strain, and the volume fraction of grain boundaries of FAp as a function of milling time. Mechanical activation up to $15 \mathrm{~h}$ leads to a rapid decrease in the crystallite size to less than $16 \mathrm{~nm}$, and a large increase 
in the volume fraction of grain boundary to $17.55 \%$. Upon $15 \mathrm{~h}$ of mechanical activation, the crystallite size and the volume fraction of grain boundary reach about $16 \mathrm{~nm}$ and $16.54 \%$, respectively. The evaluation of the lattice strain indicates that the lattice strain significantly increased with mechanical activation until $15 \mathrm{~h}$, and then decreased slightly with further milling up to $20 \mathrm{~h}$. The determined amounts of the crystallite size and the lattice strain of $\mathrm{TiO}_{2}$ as reinforcement are presented in Figure $18 \mathrm{~d}$. The crystallite size of $\mathrm{TiO}_{2}$ remains nearly constant with milling until $10 \mathrm{~h}$, and then decreases severely with further mechanical activation up to $15 \mathrm{~h}$. After $20 \mathrm{~h}$ of milling, the lattice strain decreases which leads to an increase in the crystallite size. According to data presented in Figure 18 with further mechanical activation up to $20 \mathrm{~h}$ for both matrix and reinforcement, the lattice strain can be decreased at higher milling intensities because of the enhanced dynamical recrystallisation. Because the calcium phosphate ceramics with higher crystallinity degree has lower activity towards bioresorption and lower solubility in physiological environment (Sanosh et al., 2009), thermal recovery of crystallinity was performed at $650 \mathrm{C}$ for $2 \mathrm{~h}$. Some increase in the peak intensity of the crystalline FAp phase was observed in the XRD pattern (Figure 18e). The crystalline phase of titanium dioxide $\left(\mathrm{TiO}_{2}\right)$ similarly appeared upon annealing. After heat treatment, the breadth of the fundamental diffraction peaks decrease as compared to the results of the milled powder which can be attributed to an increase in crystallite size and a decrease in lattice strain. The determined amounts of the structural features indicated that the crystallite size and lattice strain of FAp reached $43.3 \mathrm{~nm}$ and $0.30 \%$, respectively.
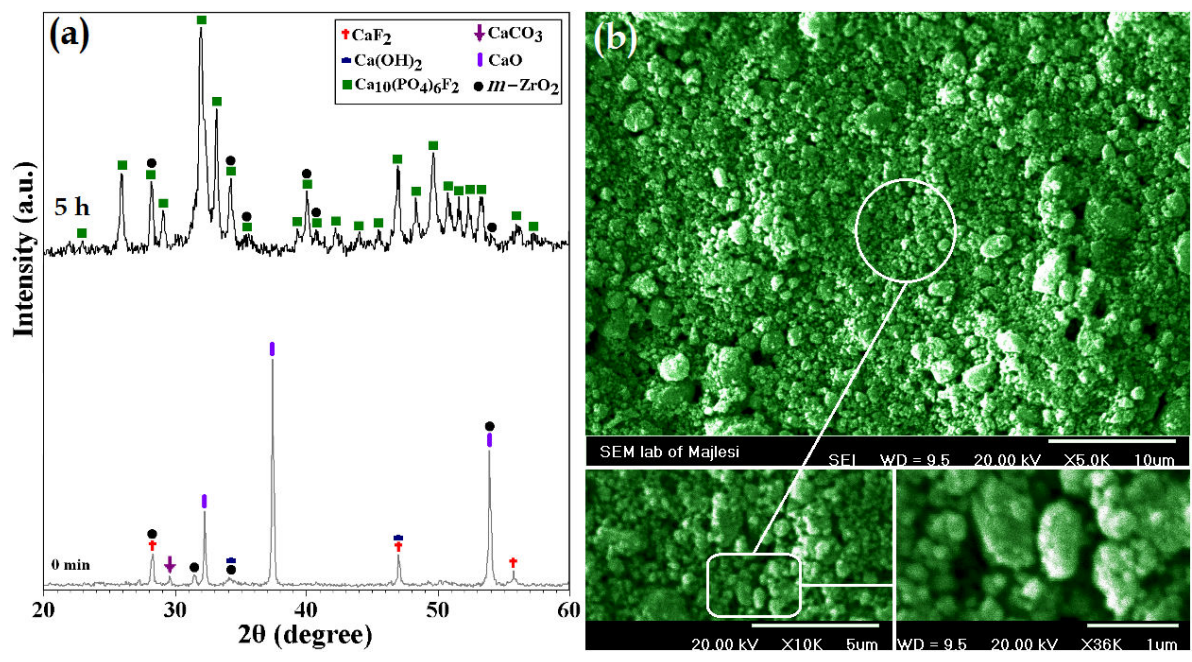

Figure 20. XRD patterns and morphological features of the $\mathrm{FAp}-\mathrm{ZrO}_{2}$ composite nanopowders after $5 \mathrm{~h}$ of milling.

The SEM micrograph, EDX result, and TEM image of the mechanosynthesized FAp-20 wt. $\% \mathrm{TiO}_{2}$ nanocomposite after $20 \mathrm{~h}$ of mechanical activation time are shown in Figure 19. After $20 \mathrm{~h}$ of milling, the mean size of powder particles decreased due to severe mechanical deformation introduced into the powder. It also emerged from SEM image, that the fine agglom- 
erates consist of significantly finer agglomerates/particles that cannot be seen individually in micrographs because of their exceptionally small sizes. Therefore, the size and morphology of fine powders was determined by using transmission electron microscopy. The results of measurements of elemental composition by EDX confirm that very homogeneous distribution of components is formed during one step mechanochemical process particularly after 20 $\mathrm{h}$ of milling. The results of EDX analysis also reveal that no chemically stable contaminants are detected due to the excessive adhesion of powders to the milling media. From TEM images it is clearly seen that the synthesized powder after $20 \mathrm{~h}$ of milling has an appropriate homogeneity. Also, the particles of products are in average size of about $15 \mathrm{~nm}$ after $20 \mathrm{~h}$ of milling, respectively. Due to high surface energy, the nanostructured materials can improve the sinterability and, thus, improve mechanical properties (Suryanarayana, 2001). Of course, sintering behavior not only depends on particle size, but also on particle size distribution and morphology of the powder particles. Large particle size along with hard agglomerates shows lower densification in calcium phosphate ceramics. On the other hand, difference in shrinkage between the agglomerates is also responsible to produce small cracks in the sintered calcium phosphate-based ceramic (Banerjee et al., 2007). Therefore, preparation of agglomerate free or soft agglomerated nanostructured $\mathrm{FAp}-20 \mathrm{wt} . \% \mathrm{TiO}_{2}$ can be an important parameter to achieve good mechanical properties for dense nanostructure. The results of SEM and TEM images suggest that the formation of $\mathrm{FAp}-20 \mathrm{wt} . \% \mathrm{TiO}_{2}$ nanocomposite after $20 \mathrm{~h}$ of milling does not accompany hard agglomerates and, therefore, the synthesized powder can present appropriate mechanical properties.

\subsubsection{Fluorapatite-Zirconia $\left(\mathrm{FAp}-\mathrm{ZrO}_{2}\right)$ nanocomposite}

Among the reinforcement materials of ceramic-based bionanocomposites, $\mathrm{ZrO}_{2}$ as a bioinert reinforcement has been studied extensively because of its relatively higher mechanical strength and toughness (Rao \& Kannan, 2002; Ben Ayed \& Bouaziz, 2008; Evis, 2007). However, the addition of $\mathrm{ZrO}_{2}$ results in lowering the decomposition temperature of microcrystalline HAp- and FHAp-based composites below the sintering temperature which causes an adverse influence on the mechanical properties (Kim et al., 2003). These phenomena are related to structural features of composite that are affected by the synthesis process. Generally, in order to prepare $\mathrm{HAp} / \mathrm{FHAp}-\mathrm{ZrO}_{2}$ composites, calcium phosphate source chemicals and $\mathrm{ZrO}_{2}$ powders are mixed, cold pressed and then sintered at high temperatures (Rao \& Kannan, 2002). Under these conditions, the resulting product could have microcrystalline structure. Since the nanocrystalline structure compared to the microcrystalline structure is more important to achieve high thermal stability and mechanical properties, the $\mathrm{FAp}-\mathrm{ZrO} \mathrm{C}_{2} \mathrm{com}$ posites with nanostructural characteristics are preferred for medical applications. In fact, the composite nanopowders can improve the sinterability as well as mechanical properties due to high surface energy. For all these reasons, our research group was considered to synthesis of $\mathrm{FAp}-\mathrm{ZrO}_{2}$ nanocomposite with appropriate structural features via one step mechanochemical process. For this aim, commercially available calcium oxide $(\mathrm{CaO})$, phosphorous pentoxide $\left(\mathrm{P}_{2} \mathrm{O}_{5}\right)$, calcium fluoride $\left(\mathrm{CaF}_{2}\right)$, and monoclinic zirconia $\left(m-\mathrm{ZrO}_{2}\right)$ were used as starting reagents. The mechanochemical synthesis was performed in a planetary ball mill without using any process control agent (PCA). 
Figure 20 shows the XRD patterns and SEM images of $\mathrm{FAp}-\mathrm{ZrO}_{2}$ composite nanopowders after mechanical activation for $5 \mathrm{~h}$. An XRD pattern of the mixture before milling is also given in the same figure for comparison. As can be seen in this figure, only sharp characteristic peaks of $\mathrm{CaO}$ and $\mathrm{CaF}_{2}$ could be detected at the initial mechanical activation of starting powder mixture. Phosphoric acid was formed immediately upon addition of $\mathrm{P}_{2} \mathrm{O}_{5}$ to the reaction mixture due to very high hydrophilic of $\mathrm{P}_{2} \mathrm{O}_{5}$. Therefore, characteristic peaks of $\mathrm{P}_{2} \mathrm{O}_{5}$ could not be observed. On the other hand, the $\mathrm{CaO}$ is not stable and will spontaneously react with $\mathrm{H}_{2} \mathrm{O}$ and $\mathrm{CO}_{2}$ from the air that leading to formation of $\mathrm{Ca}(\mathrm{OH})_{2}$ and $\mathrm{CaCO}_{3}$ in powder mixture. According to the XRD patterns, it can be seen that after $5 \mathrm{~h}$ of milling, all the peaks corresponding to $\mathrm{CaO}$ have vanished and only those belonging to $\mathrm{FAp}$ and $m-\mathrm{ZrO}_{2}$ were visible. Figure $20 \mathrm{~b}$ shows the morphological characteristics of the $\mathrm{FAp}-\mathrm{ZrO}_{2}$ composite nanopowders after $5 \mathrm{~h}$ of milling at different magnifications. According to this figure, a homogeneous microstructure was obtained after $5 \mathrm{~h}$ of milling which is important for the improvement in mechanical properties.

\section{Conclusion and future directions}

Hydroxyapatite- and fluorapatite-based nanocomposite powders have been developed and demonstrate huge potential for a variety of biomedical applications such as controlled drug release, bone cements, tooth paste additive, and dental implants. Different types of calcium phosphate-based nanocomposites can be synthesized by various approaches for instance wet chemical methods, hydrothermal processes, solid-state reaction, sol-gel method, and mechanochemical processes. Compared to various synthesis processes, mechanosynthesis method present a number of advantages such as high efficiency and enabling to synthesis a wide range of novel advanced materials (nanocomposites). It has been proved that the structural, mechanical, and biological properties of bioceramics can be significantly improved by using calcium phosphate-based nanocomposites as the advanced materials. For this reason, many attempts have been made to improve the mechanical properties as well as structural features of bioceramics through the incorporation of ceramic second phases. Mechanochemical synthesis of hydroxyapatite- and fluorapatite-based nanocomposite powders are of great interest and should be further explored. Although mechanochemical process have demonstrated their great potential for synthesis of hydroxyapatite- and fluorapatite-based nanocomposite powders, several challenges still remain. Mechanosynthesis of nanocomposites with precisely controlling their chemical composition, phases, biological characteristics, mechanical properties, and interfacial features is still a challenging task. Depending on the preparation circumstances (milling atmosphere, milling time, milling temperature, and type of milling media) and chemical composition of initial materials, the properties and performance of the nanocomposites can vary significantly; therefore, the ability to reproduce calcium phosphate-based nanocomposites with unique characteristics is very important for their wide use as biomaterials. With the increased interests and intensive research and development in the field of mechanochemistry, it is expected that, mechanosynthesized nanocompo- 
sites will have a promising future and will make a significant influence on the advanced materials industry.

\section{Acknowledgements}

The authors are grateful to research affairs of Islamic Azad University, Najafabad Branch and Iranian Nanotechnology Initiative Council (INIC) for supporting this research.

\section{Author details}

Bahman Nasiri-Tabrizi ${ }^{1}$, Abbas Fahami ${ }^{1}$, Reza Ebrahimi-Kahrizsangi ${ }^{1}$ and Farzad Ebrahimi ${ }^{2}$ 1 Materials Engineering Department, Najafabad Branch, Islamic Azad University, Najafabad, Isfahan, Iran

2 Department of Mechanical Engineering, Faculty of Engineering, Imam Khomeini International University, Qazvin, Iran

\section{References}

[1] Adamopoulos, O., \& Papadopoulos, T. (2007). Nanostructured bioceramics for maxillofacial applications. Journal of Materials Science: Materials in Medicine, 18, 1587-1597.

[2] Adolfsson, E., Nygren, N., \& Hermansson, L. (1999). Decomposition mechanisms in aluminum oxide-apatite systems. Journal of the American Ceramic Society, 82, 2909-2912.

[3] Avvakumov, E., Senna, M., \& Kosova, N. (2002). Soft mechanochemical synthesis: A basis for new chemical technologies,, Kluwer Academic Publishers.

[4] Balamurugan, A., Kannan, S., \& Rajeswari, S. (2002). Bioactive sol-gel hydroxyapatite surface for biomedical application-in vitro study. Trends in Biomaterials \& Artificial Organs, 16, 18-20.

[5] Balaz, P. (2008). Mechanochemistry in Nanoscience and Minerals Engineering, Springer.

[6] Banerjee, A., Bandyopadhyay, A., \& Bose, S. (2007). Hydroxyapatite nanopowders: synthesis, densification and cell materials interaction. Materials Science and Engineering $C, 27,729-735$.

[7] Barinov, S. M., Shvorneva, L. I., Ferro, D., Fadeeva, I. V., \& Tumanov, S. V. (2004). Solid solution formation at the sintering of hydroxyapatite-fluorapatite ceramics. Science and Technology of Advanced Materials, 5, 537-541. 
[8] Ben, Ayed. F., \& Bouaziz, J. (2008). Sintering of tricalcium phosphate-fluorapatite composites with zirconia. Journal of the European Ceramic Society, 28, 1995-2002.

[9] Bose, S., Xue, W., Banerjee, A., \& Bandyopadhyay, A. (2009). Spherical and anisotropic hydroxyapatite nanocrystals Challa S. S. R. Kumar ed. Nanomaterials for the Life Sciences 2, Nanostructured Oxides, WILEY-VCH Verlag GmbH \& Co, 407-447.

[10] Bouslama, N., Ben, Ayed. F., \& Bouaziz, J. (2009). Sintering and mechanical properties of tricalcium phosphate-fluorapatite composites. Ceramics International, 35, 1909-1917.

[11] Cacciotti, I., Bianco, A., Lombardi, M., \& Montanaro, L. (2009). Mg-substituted hydroxyapatite nanopowders: Synthesis, thermal stability and sintering behaviour. Journal of the European Ceramic Society, 29, 2969-2978.

[12] Cao, H., \& Kuboyama, N. (2010). A biodegradable porous composite scaffold of PGA/ $\beta$-TCP for bone tissue engineering. Bone, 46, 386-395.

[13] Chen-W, Ch., Riman, R. E., Ten, Huisen. K. S., \& Brown, K. (2004). Mechanochemical-hydrothermal synthesis of hydroxyapatite from nonionic surfactant emulsion precursors. Journal of Crystal Growth, 270, 615-623.

[14] Cheng, K., Zhang, S., \& Weng, W. (2006). Sol-gel preparation of fluoridated hydroxyapatitein $\mathrm{Ca}\left(3_{2}-\mathrm{PO}(\mathrm{OH})_{3-x}(\mathrm{OEt})_{x}-\mathrm{HPF}_{6}\right.$ system. Journal of Sol-Gel Science and Technology, 38, 13-17.

[15] Chen, Y., \& Miao, X. (2005). Thermal and chemical stability of fluorohydroxyapatite ceramics with different fluorine contents. Biomaterials, 26, 1205-1210.

[16] Choi-Y, W., Kim-E, H., Oh, S. Y., \& Koh, Y. H. (2010). Synthesis of poly(ع-caprolactone)/hydroxyapatite nanocomposites using in-situ co-precipitation. Materials Science and Engineering C, 30, 777-780.

[17] De Castro, C. L., \& Mitchell, B. S. (2002). Synthesis functionalization and surface treatment of nanoparticles. Nanoparticles from mechanical attrition, Stevenson Ranch, CA: American Scientific Publishers, 1-14.

[18] Ducheyne, P., \& Qiu, Q. (1999). Bioactive ceramics: the effect of surface reactivity on bone formation and bone cell function. Biomaterials, 20, 2287-2303.

[19] Ebrahimi-Kahrizsangi, R., Nasiri-Tabrizi, B., \& Chami, A. (2010). Synthesis and characterization of fluorapatite-titania $\left(\mathrm{FAp}-\mathrm{TiO}_{2}\right)$ nanocomposite via mechanochemical process. Solid State Sciences, 12, 1645-1651.

[20] Ebrahimi-Kahrizsangi, R., Nasiri-Tabrizi, B., \& Chami, A. (2011). Characterization of single-crystal fluorapatite nanoparticles synthesized via mechanochemical method. Particuology, 9, 537-544.

[21] El Briak-Ben, Abdeslam. H., Ginebra, M. P., Vert, M., \& Boudeville, P. (2008). Wet or dry mechanochemical synthesis of calcium phosphates? Influence of the water content on DCPD-CaO reaction kinetics. Acta Biomaterialia, 4, 378-386. 
[22] Enayati-Jazi, M., Solati-Hashjin, M., Nemati, A., \& Bakhshi, F. (2012). Synthesis and characterization of hydroxyapatite/titania nanocomposites using in situ precipitation technique. Superlattices and Microstructures, 51, 877-885.

[23] Evis, Z. (2007). Reactions in hydroxylapatite-zirconia composites. Ceramics International, 33, 987-991.

[24] Fahami, A., Ebrahimi-Kahrizsangi, R., \& Nasiri-Tabrizi, B. (2011). Mechanochemical synthesis of hydroxyapatite/titanium nanocomposite. Solid State Sciences, 13, 135-141.

[25] Fahami, A., Nasiri-Tabrizi, B., \& Ebrahimi-Kahrizsangi, R. (2012). Synthesis of calcium phosphate-based composite nanopowders by mechanochemical process and subsequent thermal treatment. Ceramics International.

[26] Farzadi, A., Solati-Hashin, M., Bakhshi, F., \& Aminian, A. (2011). Synthesis and characterization of hydroxyapatite/ $\beta$-tricalcium phosphate nanocomposites using microwave irradiation. Ceramics International, 37, 65-71.

[27] Fathi, M. H., \& Mohammadi Zahrani, E. (2009). Fabrication and characterization of fluoridated hydroxyapatite nanopowders via mechanical alloying. Journal of Alloys and Compounds, 475, 408-414.

[28] Fathi, M. H., Mohammadi Zahrani, E., \& Zomorodian, A. (2009). Novel fluorapatite/ niobium composite coating for metallic human body implants. Materials Letters, 63, 1195-1198.

[29] Fini, M., Savarino, L., Nicoli, Aldini. N., Martini, L., Giavaresi, G., Rizzi, G., Martini, D., Ruggeri, A., Giunti, A., \& Giardino, R. (2003). Biomechanical and histomorphometric investigations on two morphologically differing titanium surfaces with and without fluorohydroxyapatite coating: An experimental study in sheep tibiae. Biomaterials, 24, 3183-3192.

[30] Gergely, G., Wéber, F., Lukács, I., Tóth, A. L., Horváth, Z. E., Mihály, J., \& Balázsi, C. (2010). Preparation and characterization of hydroxyapatite from eggshell. Ceramics International, 36, 803-806.

[31] Gonzalez, G., Sagarzazu, A., \& Villalba, R. (2006). Mechanochemical transformation of mixtures of $\mathrm{Ca}(\mathrm{OH})_{2}$ and $\left(\mathrm{NH}_{4}\right)_{2} \mathrm{HPO}_{4}$ or 2O5. Materials Research Bulletin, 41, 1902-1916.

[32] Gu, M., Huang, C., Xiao, S., \& Liu, H. (2008). Improvements in mechanical properties of $\mathrm{TiB}_{2}$ ceramics tool materials by dispersion of $\mathrm{Al}_{2} \mathrm{O}_{3}$ particles. Materials Science and Engineering A, 486, 167-170.

[33] Gu, Y. W., Loh, N. H., Khor, K. A., Tor, S. B., \& Cheang, P. (2002). Spark plasma sintering of hydroxyapatite powders. Biomaterials, 23, 37-43.

[34] Honarmandi, P., Honarmandi, P., Shokuhfar, A., Nasiri-Tabrizi, B., \& Ebrahimi-Kahrizsangi, R. (2010). Milling media effects on synthesis, morphology and structural 
characteristics of single crystal hydroxyapatite nanoparticles. Advances in Applied Ceramics, 109, 117-122.

[35] Hsu, Y. H., Turner, I. G., \& Miles, A. W. (2007). Fabrication and mechanical testing of porous calcium phosphate bioceramic granules. Journal of Materials Science: Materials in Medicine, 18, 1931-1937.

[36] Hu, H., Liu, X., \& Ding, Ch. (2010). Preparation and in vitro evaluation of nanostructured $\mathrm{TiO}_{2} / \mathrm{TCP}$ composite coating by plasma electrolytic oxidation. Journal of Alloys and Compounds, 498, 172-178.

[37] Jallot, E., Nedelec, J. M., Grimault, A. S., Chassot, E., Grandjean-Laquerriere, A., Laquerriere, P., \& Laurent-Maquin, D. (2005). STEM and EDXS characterisation of physico-chemical reactions at the periphery of sol-gel derived Zn-substituted hydroxyapatites during interactions with biological fluids. Colloids and Surfaces B: Biointerfaces, 42, 205-210.

[38] Jin, H. H., Min, S. H., Song, Y. K., Park, H., Ch, , \& Yoon, S. Y. (2010). Degradation behavior of poly(lactide-co-glycolide)/ $\beta$-TCP composites prepared using microwave energy. Polymer Degradation and Stability, 95, 1856-1861.

[39] Kalita, S. J., Bhardwaj, A., \& Bhatt, H. A. (2007). Nanocrystalline calcium phosphate ceramics in biomedical engineering. Materials Science and Engineering C, 27, 441-449.

[40] Kano, J., Zhang, Q., Saito, F., Baron, M., \& Nzihou, A. (2006). Synthesis of hydroxyapatite with the mechanochemical treatment products of PVC and $\mathrm{CaO}$ Trans I Chem E, Part B. Process Safety and Environmental Protection, 84(B4), 309-312.

[41] Khaghani-Dehaghani, M. A., Ebrahimi-Kahrizsangi, R., Setoudeh, N., \& Nasiri-Tabri$\mathrm{zi}, \mathrm{B}$. (2011). Mechanochemical synthesis of $\mathrm{Al}_{2} \mathrm{O}_{3}-\mathrm{TiB}_{2}$ nanocomposite powder from $\mathrm{Al}-\mathrm{TiO}_{2}-\mathrm{H}_{3} \mathrm{BO}_{3}$ mixture. Int. Journal of Refractory Metals and Hard Materials, 29, 244-249.

[42] Kim, H. W., Kong, Y. M., Bae, Ch. J., Noh, Y. J., \& Kim, H. E. (2004b). Sol-gel derived fluor-hydroxyapatite biocoatings on zirconia substrate. Biomaterials, 25, 2919-2926.

[43] Kim, H. W., Kong, Y. M., Koh, Y. H., \& Kim, H. E. (2003). Pressureless sintering and mechanical and biological properties of fluor-hydroxyapatite composites with zirconia. Journal of the American Ceramic Society, 86, 2019-2026.

[44] Kim, H. W., Li, L. H., Koh, Y. H., Knowles, J. C., \& Kim, H. E. (2004a). Sol-Gel preparation and properties of fluoride-substituted hydroxyapatite powders. Journal of the American Ceramic Society, 87, 1939-1944.

[45] Kivrak, N., \& Tas, A. C. (1998). Synthesis of calcium hydroxyapatite-tricalcium phosphate composite bioceramic powders and their sintering behavior. Journal of the American Ceramic Society, 81, 2245-2252.

[46] Komlev, V. S., Barinov, S. M., Orlovskii, V. P., \& Kurdyumov, S. G. (2001). Porous Ceramic Granules of Hydroxyapatite. Refractories and Industrial Ceramics, 42, 242-244. 
[47] Kong, Y. M., Kim, S., \& Kim, H. E. (1999). Reinforcement of hydroxyapatite bioceramic by addition of $\mathrm{ZrO}_{2}$ coated with $\mathrm{Al}_{2} \mathrm{O}_{3}$. Journal of the American Ceramic Society, 82, 2963-2968.

[48] Kurmaev, E. Z., Matsuya, S., Shin, S., Watanabe, M., Eguchi, R., Ishiwata, Y., Takeuchi, T., \& Iwami, M. (2002). Observation of fluorapatite formation under hydrolysis of tetracalcium phosphate in the presence of KF by means of soft X-ray emission and absorption spectroscopy. Journal of Materials Science: Materials in Medicine, 13, 33-36.

[49] Landi, E., Tampieri, A., Celotti, G., \& Sprio, S. (2000). Densification behavior and mechanisms of synthetic hydroxyapatites. Journal of the European Ceramic Society, 20, 2377-2387.

[50] Lee-H, H., Shin, U. S., Won-E, J., \& Kim-W, H. (2011). Preparation of hydroxyapatitecarbon nanotube composite nanopowders. Materials Letters, 65, 208-211.

[51] Liu, F., Wang, F., Shimizu, T., Igarashi, K., \& Zhao, L. (2006). Hydroxyapatite formation on oxide films containing $\mathrm{Ca}$ and $\mathrm{P}$ by hydrothermal treatment. Ceramics International, 32, 527-531.

[52] Marchi, J., Greil, P., Bressiani, J. C., Bressiani, A., \& Müller, F. (2009). Influence of synthesis conditions on the characteristics of biphasic calcium phosphate powders. International Journal of Applied Ceramic Technology, 6, 60-71.

[53] Mayera, I., \& Featherstone, J. D. B. (2000). Dissolution studies of Zn-containing carbonated hydroxyapatites. Journal of Crystal Growth., 219, 98-101.

[54] Mobasherpour, I., Solati-Hashjin, M., \& Kazemzadeh, A. (2007). Synthesis of nanocrystalline hydroxyapatite by using precipitation method. Journal of Alloys and Compounds, 430, 330-333.

[55] Mochales, C., El Briak-Ben, Abdeslam. H., Ginebra, M. P., Terol, A., Planell, J. A., \& Boudeville, Ph. (2004). Dry mechanochemical synthesis of hydroxyapatites from DCPD and CaO: influence of instrumental parameters on the reaction kinetics. Biomaterials, 25, 1151-1158.

[56] Mishra, S. K., Das, S. K., \& Pathak, L. C. (2006). Sintering behavior of self-propagating high temperature synthesized $\mathrm{ZrB}_{2}-\mathrm{Al}_{2} \mathrm{O}_{3}$ composite powder. Materials Science and Engineering $A, 426,229-34$.

[57] Mohammadi, Zahrani. E., \& Fathi, M. H. (2009). The effect of high-energy ball milling parameters on the preparation and characterization of fluorapatite nanocrystalline powder. Ceramics International, 35, 2311-2323.

[58] Nakano, T., Tokumura, A., \& Umakoshi, Y. (2002). Variation in crystallinity of hydroxyapatite and the related calcium phosphates by mechanical grinding and subsequent heat treatment. Metallurgical and Materials Transactions A, 33, 521-528. 
[59] Nasiri-Tabrizi, B., Honarmandi, P., Ebrahimi-Kahrizsangi, R., \& Honarmandi, P. (2009). Synthesis of nanosize single-crystal hydroxyapatite via mechanochemical method. Materials Letters, 63, 543-546.

[60] Nath, S., Tripathi, R., \& Basu, B. (2009). Understanding phase stability, microstructure development and biocompatibility in calcium phosphate-titania composites, synthesized from hydroxyapatite and titanium powder mixture. Materials Science and Engineering C, 29, 97-107.

[61] Nayar, S., Sinha, M. K., Basu, D., \& Sinha, A. (2006). Synthesis and sintering of biomimetic hydroxyapatite nanoparticles for biomedical applications. Journal of Materials Science: Materials in Medicine, 17, 1063-1068.

[62] Nikcevic, I., Jokanovic, V., Mitric, M., Nedic, Z., Makovec, D., \& Uskokovic, D. (2004). Mechanochemical synthesis of nanostructured fluorapatite/fluorhydroxyapatite and carbonated fluorapatite/fluorhydroxyapatite. Journal of Solid State Chemistry, $177,2565-2574$.

[63] Otsuka, M., Matsuda, Y., Hsu, J., Fox, J. L., \& Higuchi, W. I. (1994). Mechanochemical synthesis of bioactive material: effect of environmental conditions on the phase transformation of calcium phosphates during grinding. Bio-Medical Materials and Engineering, 4, 357-362.

[64] Palmer, C. A., \& Anderson, J. J. B. (2001). Position of the American dietetic association: The impact of fluoride on health. Journal of the American Dietetic Association, 101, 126-132.

[65] Pan, H., Tao, J., Yu, X., Fu, L., Zhang, J., Zeng, X., Xu, G., \& Tang, R. (2008). Anisotropic demineralization and oriented assembly of hydroxyapatite crystals in enamel: smart structures of biominerals. Journal of Physical Chemistry B, 112, 7162-7165.

[66] Pushpakanth, S., Srinivasan, B., Sreedhar, B., \& Sastry, T. P. (2008). An in situ approach to prepare nanorods of titania hydroxyapatite $\left(\mathrm{TiO}_{2}-\mathrm{HAp}\right)$ nanocomposite by microwave hydrothermal technique. Materials Chemistry and Physics, 107, 492-498.

[67] Rajkumar, M., Meenakshisundaram, N., \& Rajendran, V. (2011). Development of nanocomposites based on hydroxyapatite/sodium alginate: Synthesis and characterisation. Materials Characterization, 62, 469-479.

[68] Rameshbabu, N., Sampath, Kumar. T. S., \& Prasad, Rao. K. (2006). Synthesis of nanocrystalline fluorinated hydroxyapatite by microwave processing and its in vitro dissolution study. Bulletin of Material Science, 29, 611-615.

[69] Ramesh, S., Tan, C. Y., Tolouei, R., Amiriyan, M., Purbolaksono, J., Sopyan, I., \& Teng, W. D. (2012). Sintering behavior of hydroxyapatite prepared from different routes. Materials and Design, 34, 148-154.

[70] Rao, R. R., \& Kannan, T. S. (2002). Synthesis and sintering of hydroxyapatite-zirconia composites. Materials Science and Engineering C, 20, 187-193. 
[71] Ren, F., Leng, Y., Xin, R., \& Ge, X. (2010). Synthesis, characterization and ab initio simulation of magnesium-substituted hydroxyapatite. Acta Biomaterialia, 6, 2787-2796.

[72] Rhee, S. H. (2002). Synthesis of hydroxyapatite via mechanochemical treatment. Biomaterials, 23, 1147-1152.

[73] Sanosh, K. P., Chu, M. C., Balakrishnan, A., Lee, Y. J., Kim, T. N., \& Cho, S. J. (2009). Synthesis of nano hydroxyapatite powder that simulate teeth particle morphology and composition. Current Applied Physics, 9, 1459-1462.

[74] Schneider, O. D., Stepuk, A., Mohn, Dirk., Luechinger, Norman. A., Feldman, K., \& Stark, W. J. (2010). Light-curable polymer/calcium phosphate nanocomposite glue for bone defect treatment. Acta Biomaterialia, 6, 2704-2710.

[75] Silva, C. C., Graca, M. P. F., Valente, M. A., \& Sombra, A. S. B. (2007). Crystallite size study of nanocrystalline hydroxyapatite and ceramic system with titanium oxide obtained by dry ball milling. Journal of Materials Science, 42, 3851-3855.

[76] Silva, C. C., Pinheiro, A. G., Figueiro, S. D., Goes, J. C., Sasaki, J. M., Miranda, M. A. R., \& Sombra, A. S. B. (2002). Piezoelectric properties of collagen-nanocrystalline hydroxyapatite composites. Journal of Materials Science, 37, 2061-2070.

[77] Silva, C. C., Pinheiro, A. G., Miranda, M. A. R., Goes, J. C., \& Sombra, A. S. B. (2003). Structural properties of hydroxyapatite obtained by mechanosynthesis. Solid State Sciences, 5, 553-558.

[78] Silva, C. C., Valente, M. A., Graça, M. P. F., \& Sombra, A. S. B. (2004). Preparation and optical characterization of hydroxyapatite and ceramic systems with titanium and zirconium formed by dry high-energy mechanical alloying. Solid State Sciences, 6, 1365-1374.

[79] Suchanek, W. L., Byrappa, K., Shuk, P., Riman, R. E., Janas, V. F., \& Ten, Huisen. K. S. (2004). Preparation of magnesium-substituted hydroxyapatite powders by the mechanochemical-hydrothermal method. Biomaterials, 25, 4647-4657.

[80] Sul, Y. T. (2008). Osseoinductive magnesium-titanate implant and method of manufacturing the same, United State Patent Patent No.: US 7,452,566 B2.

[81] Sun, Y., Yang, H., \& Tao, D. (2012). Preparation and characterization of $\mathrm{Eu}^{3+}$-doped fluorapatite nanoparticles by a hydrothermal method. Ceramics International.

[82] Suryanarayana, C. (2001). Mechanical alloying and milling. Progress in Materials Science, 46, 1-184.

[83] Takacs, L. (2002). Self-sustaining reactions induced by ball milling. Progress in Materials Science, 47, 355-414.

[84] Takacs, L., Balaz, P., \& Torosyan, A. R. (2006). Ball milling-induced reduction of $\mathrm{MoS}_{2}$ with Al. Journal of Materials Science, 41, 7033-7039. 
[85] Tian, T., Jiang, D., Zhang, J., \& Lin, Q. (2008). Synthesis of Si-substituted hydroxyapatite by a wet mechanochemical method. Materials Science and Engineering C, 28, 57-63.

[86] Toriyama, M., Lavaglioli, F., , A., Krajewski, A., Celotti, G., \& Piancastelli, A. (1996). Synthesis of hydroxyapatite-based powders by mechano-chemical method and their sintering. Journal of the European Ceramic Society, 16, 429-436.

[87] Viswanath, B., \& Ravishankar, N. (2006). Interfacial reactions in hydroxyapatite/ alumina nanocomposites. Scripta Materialia, 55, 863-866.

[88] Wu-C, S., Hsu-C, H., Wu-N, Y., \& Ho-F, W. (2011). Hydroxyapatite synthesized from oyster shell powders by ball milling and heat treatment. Materials Characterization, 62, 1180-1187.

[89] Xia, Z. P., Shen, Y. Q., Shen, J. J., \& Li, Z. Q. (2008). Mechanosynthesis of molybdenum carbides by ball milling at room temperature. Journal of Alloys and Compounds, 453, 185-90.

[90] Yeong, K. C. B., Wang, J., \& Ng, S. C. (2001). Mechanochemical synthesis of nanocrystalline hydroxyapatite from $\mathrm{CaO}$ and $\mathrm{CaHPO}_{4}$. Biomaterials, 22, 2705-2712.

[91] Zeng, H., Chittur, K. K., \& Lacefield, W. R. (1999). Analysis of bovine serum albumin adsorption on calcium phosphate and titanium surfaces. Biomaterials, 20, 377-384.

[92] Zhang, H., Zhu, Q., \& Xie, Z. (2005). Mechanochemical-hydrothermal synthesis and characterization of fluoridated hydroxyapatite. Materials Research Bulletin, 40, 1326-1334.

[93] Zhou, H., \& Lee, J. (2011). Nanoscale hydroxyapatite particles for bone tissue engineering. Acta Biomaterialia, 7, 2769-2781.

[94] Hench, Larry L. (1998). Bioceramics. Journal of the American Ceramic Society, 81(7), 1705-1728. 
